LAÍS LIMEIRA RODRIGUES

Avaliação das lesões do sistema nervoso central em cães senis: caracterização histológica e imuno-histoquímica

São Paulo

2019 


\section{LAÍS LIMEIRA RODRIGUES}

Avaliação das lesões do sistema nervoso central em cães senis: caracterização histológica e imuno-histoquímica

Dissertação apresentada ao Programa de PósGraduação em Patologia Experimental e Comparada da Faculdade de Medicina Veterinária e Zootecnia da Universidade de São Paulo para a obtenção do título de Mestre em Ciências

Departamento:

Patologia

Área de Concentração:

Patologia Experimental e Comparada

Orientador:

Prof. Dr. Paulo César Maiorka

São Paulo

2019 
Autorizo a reprodução parcial ou total desta obra, para fins acadêmicos, desde que citada a fonte.

DADOS INTERNACIONAIS DE CATALOGAÇÃO NA PUBLICAÇÃO

(Biblioteca Virginie Buff D’Ápice da Faculdade de Medicina Veterinária e Zootecnia da Universidade de São Paulo)

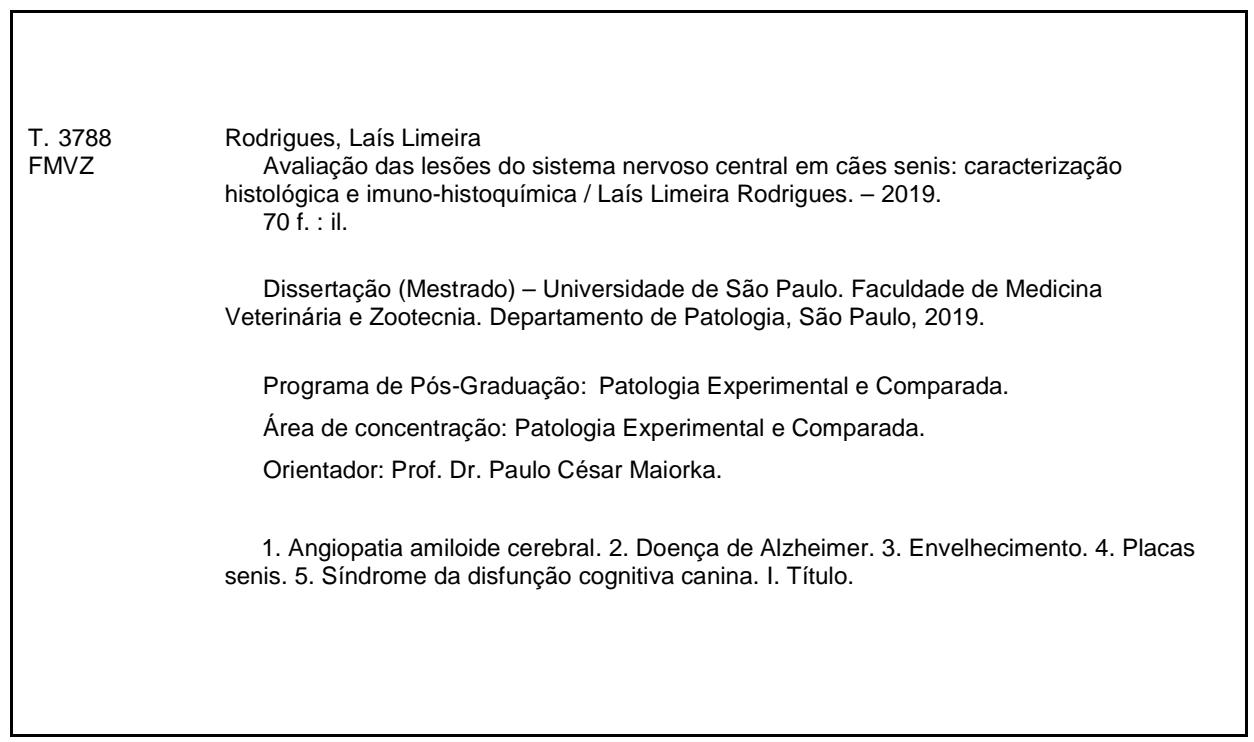

Ficha catalográfica elaborada pela bibliotecária Maria Aparecida Laet, CRB 5673-8, da FMVZ/USP. 


\section{CERTIFICADO}

Certificamos que a proposta intitulada "Avaliação das lesões do sistema nervoso central em cães senis: caracterização histológica e imuno-histoquímica", protocolada sob o CEUA no 5509280119 (ID 006251), sob a responsabilidade de Paulo César Maiorka e equipe; Laís Limeira Rodrigues - que envolve a produção, manutenção e/ou utilização de animais pertencentes ao filo Chordata, subfilo Vertebrata (exceto o homem), para fins de pesquisa científica ou ensino - está de acordo com os preceitos da Lei 11.794 de 8 de outubro de 2008, com o Decreto 6.899 de 15 de julho de 2009, bem como com as normas editadas pelo Conselho Nacional de Controle da Experimentação Animal (CONCEA), e foi aprovada pela Comissão de Ética no Uso de Animais da Faculdade de Medicina Veterinária e Zootecnia da Universidade de São Paulo (CEUA/FMVZ) na reunião de 07/03/2019.

We certify that the proposal "Evaluation of central nervous system lesions in senile dogs: histological and immunohistochemical characterization", utilizing 46 Dogs (males and females), protocol number CEUA 5509280119 (ID 006251), under the responsibility of Paulo César Maiorka and team; Laís Limeira Rodrigues - which involves the production, maintenance and/or use of animals belonging to the phylum Chordata, subphylum Vertebrata (except human beings), for scientific research purposes or teaching - is in accordance with Law 11.794 of October 8, 2008, Decree 6899 of July 15, 2009, as well as with the rules issued by the National Council for Control of Animal Experimentation (CONCEA), and was approved by the Ethic Committee on Animal Use of the School of Veterinary Medicine and Animal Science (University of São Paulo) (CEUA/FMVZ) in the meeting of 03/07/2019.

Finalidade da Proposta: Pesquisa

Vigência da Proposta: de 02/2019 a 06/2019 Área: Patologia Experimental E Comparada

Origem: Amostras biológicas estocadas

Espécie: Cães sexo: Machos e Fêmeas idade: 6 a 216 meses $\quad$ N: 46

Linhagem: diversas raças

Peso: 1 a $50 \mathrm{~kg}$

Local do experimento: Serviço de Patologia da FMVZ-USP- Campus São Paulo

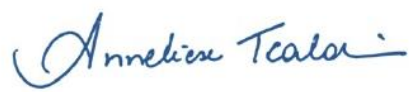

Profa. Dra. Anneliese de Souza Traldi Presidente da Comissão de Ética no Uso de Animais Faculdade de Medicina Veterinária e Zootecnia da Universidade de São Paulo

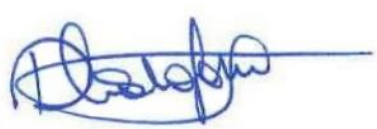

Roseli da Costa Gomes Secretária

Faculdade de Medicina Veterinária e Zootecnia da Universidade de São Paulo 


\section{FOLHA DE AVALIAÇÃO}

Autor: RODRIGUES, Laís Limeira

Título: Avaliação das lesões do sistema nervoso central em cães senis: caracterização histológica e imuno-histoquímica.

Dissertação apresentada ao Programa de PósGraduação em Patologia Experimental e Comparada da Faculdade de Medicina Veterinária e Zootecnia da Universidade de São Paulo para a obtenção do título de Mestre em Ciências

Data:

\section{Banca Examinadora}

Prof. Dr.

Instituição: Julgamento:

Prof. Dr.

Instituição: Julgamento:

Prof. Dr.

Instituição: Julgamento: 


\section{AGRADECIMENTOS}

Aos meus pais, Wilson e Nilda, pelo exemplo de honestidade e perseverança, pelo amor, pelas alegrias e conquistas compartilhadas. Ao meu irmão Rafael, pelo exemplo na profissão, pelos conselhos e amizade.

Ao meu marido e parceiro de trabalho Leonardo, pelo companheirismo, apoio e aconselhamento. Obrigada por dividir os momentos felizes e difíceis da vida comigo e por estar sempre ao meu lado. Sem você nada disso seria possível.

Aos amigos Thaís, Mariana, Rodrigo, Vivian, Marina, Isabela e Rafael pelos momentos de descontração e companheirismo, tão importantes em todos os momentos da vida.

À minha família: tios, primos, avós, cunhadas, sogros, que sempre me apoiaram incondicionalmente e nunca deixaram de vibrar com cada pequena conquista que eu alcançava.

Ao professor e amigo Paulo C. Maiorka, pela orientação, paciência, e pela confiança depositada.

Aos membros da banca, Dra. Fernanda e Dr. Caio, agradeço pela disponibilidade e contribuições indispensáveis.

A todos os professores do VPT, especialmente à prof. Claudia Mori, pelos conselhos, apoio e bons momentos compartilhados no laboratório.

Aos amigos e parceiros Danilo, Dennis, Pedro e Fábio, que com sua ajuda tornaram possível a realização desse trabalho.

Aos vários funcionários do VPT, Nelsinho, Mauro, Luciana, Cláudio, Herculano, Adriana e Milena, meu agradecimento pelo apoio e amizade. Agradeço especialmente ao Dennis, além de técnico do laboratório e colega de pósgraduação, se tornou um grande amigo. 
Aos residentes do Serviço de Patologia agradeço pela prestatividade e disponibilidade em ajudar sempre.

À CNPQ, pela concessão da bolsa de estudos de mestrado (processo 130112/2018-6). 


\section{RESUMO}

RODRIGUES, L. L. Avaliação das lesões do sistema nervoso central em cães senis: caracterização histológica e imuno-histoquímica [Evaluation of central nervous system lesions in aged dogs: histological and immunohistochemical characterization]. 70 f. Dissertação (Mestrado em Ciências) - Faculdade de Medicina Veterinária e Zootecnia, Universidade de São Paulo, São Paulo, 2019.

O presente estudo compreende a avaliação das lesões histológicas e da deposição de beta-amiloide $(A \beta)$ que ocorrem no sistema nervoso central (SNC) de cães idosos. A espécie canina tem sido utilizada como modelo animal para o estudo das doenças de humanos em que ocorre a deposição de $A \beta$ no encéfalo, tais como a doença de Alzheimer e a angiopatia amiloide cerebral (CAA). Entretanto, muitos aspectos da deposição de $A \beta$ no encéfalo de cães ainda são desconhecidos. $\mathrm{Na}$ primeira parte do estudo, é descrito um caso de doença vascular encefálica em um cão senil, de 16 anos de idade, associada a áreas de infarto agudas, sub-agudas e crônicas, além de áreas de hemorragia, com deposição da proteína precursora de beta-amiloide nos vasos do encéfalo, o que caracteriza a CAA. Em cães, diferentemente de humanos, ainda não existe uma clara associação entre CAA e hemorragias e infartos no encéfalo. Portanto, o presente caso, demonstra a ocorrência concomitante da CAA e de infartos e hemorragia no encéfalo de um cão idoso. Na segunda parte, o estudo teve como objetivo avaliar as alterações histológicas associadas à senilidade em cães, bem como avaliar a deposição de $A \beta$, por imuno-histoquímica, em diferentes áreas do encéfalo de cães idosos de diferentes raças, tanto no neurópilo, como na parede de vasos no neurópilo da substância cinzenta e em vasos leptomeníngeos. Na avaliação histológica, os principais achados foram perda e degeneração neuronais, gliose difusa, depósitos de lipofuscina e neuromelanina em neurônios, e micro-hemorragias perivasculares, achados estes compatíveis com as alterações encontradas em cães idosos. A proteína $A \beta$ foi detectada tanto sob a forma de placas senis no neurópilo da substância cinzenta, como na parede de vasos leptomeníngeos e do neurópilo nos cães senis. Considerando toda a população analisada, houve uma correlação positiva entre o aumento da idade e a deposição de $A \beta$ no SNC de cães, tanto sob a forma de placas como na parede dos vasos. Porém não houve correlação entre a 
área de deposição de $A \beta$ sob a forma de placas e a idade, em cães a partir de 8 anos. Diferentemente, na CAA, houve correlação positiva entre a área de deposição de $A \beta$ com o aumento da idade, mesmo no grupo de cães com acima de 8 anos de idade. A CAA estava associada à ocorrência de micro-hemorragias perivasculares no encéfalo, sendo que os cães com CAA possuem nove vezes mais chances de apresentarem micro-hemorragias, quando comparados àqueles que não apresentam CAA. Não houve diferença na área de deposição de $A \beta$ tanto sob a forma de placas, como em vasos, entre os córtices frontal, temporal e occipital. Em conclusão, o presente estudo demonstrou que a deposição de $A \beta$, sob a forma de placas senis ou CAA é extremamente heterogênea em cães de diferentes raças e portes. Apesar de várias características da doença em cães serem semelhantes àquelas em observadas em humanos, a escolha da raça e porte para utilização como modelo animal pode interferir no padrão de deposição de $A \beta$ no encéfalo.

Palavras-chave: Angiopatia amiloide cerebral. Doença de Alzheimer. Envelhecimento. Placas senis. Síndrome da disfunção cognitiva. 


\begin{abstract}
RODRIGUES, L. L. Evaluation of central nervous system lesions in aged dogs: histological and immunohistochemical characterization. [Avaliação das lesões do sistema nervoso central em cães senis: caracterização histológica e imunohistoquímica]. 70 f. Dissertação (Mestrado em Ciências) - Faculdade de Medicina Veterinária e Zootecnia, Universidade de São Paulo, São Paulo, 2019.
\end{abstract}

The present study comprises the evaluation of histological lesions and beta-amyloid $(A \beta)$ deposition in the central nervous system (CNS) of aged dogs. Canine species has been used as an animal model for the study of human diseases in which there is $A \beta$ deposition within the brain, such as Alzheimer's disease and cerebral amyloid angiopathy (CAA). However, many aspects of $A \beta$ deposition in the brain of dogs remain unknown. In the first part of the study, a case of a cerebrovascular disease in a 16-year-old dog, associated with acute, subacute and chronic areas of infarcts, and hemorrhages with deposition of amyloid precursor protein in brain vessels, which characterizes CAA, is described. In dogs, differently from humans, until now, there is not a clear association between CAA and brain infarcts and hemorrhages. Therefore, the case presented here, demonstrates the concomitant occurrence of CAA and infarcts and hemorrhages in the brain of an aged dog. In the second part, the aim of the study was to evaluate the histological lesions associated with aging in dogs, as well as to evaluate $A \beta$ deposition by immunohistochemistry in distinct brain areas in aged dogs of different breeds, within the neuropil of gray matter and within vessels walls of neuropil and leptomeningeal vessels. Histologically, the main findings included degeneration and neuronal loss, diffuse gliosis, lipofuscin and neuromelanin deposits within neurons, and perivascular micro-hemorrhages, which are compatible to those found in aged dogs. $A \beta$ was detected both as senile plaques within the neuropil of gray matter, as well as within the wall of vessels from the leptomeninges and neuropil of aged dogs. Considering the entire analyzed population, there was a positive correlation between aging and $A \beta$ deposition in the CNS of dogs, both in the form of senile plaques and within vessels. However, there was no correlation between the area of $A \beta$ plaque deposition and aging, when considering the group of dogs older than 8 years. Differently, in CAA, there was a positive correlation between 
$A B$ area and aging in the group of dogs older than 8 years. CAA was associated with the occurrence of perivascular micro-hemorrhages in the brain of aged dogs, and dogs with CAA had nine times more chances to develop micro-hemorrhages when compared to dogs without CAA. There wasn't a statistically difference of $A \beta$ plaque or vessel deposition between frontal, temporal or occipital cortex. In conclusion, the present study demonstrated that $A \beta$ deposition in form of senile plaques or within vessels are heterogenous in dogs of different breeds and sizes. Despite that many features of $A \beta$ deposition in dogs are similar to those observed in humans, the choice of breed and dog size to be used as an animal model can interfere in the pattern of $A \beta$ deposition within the brain.

Keywords: Aging. Alzheimer's disease. Cognitive disfunction syndrome. Cerebral amyloid angiopathy. Senile plaques. 
1

2 MÚLTIPLOS INFARTOS E HEMORRAGIAS NO SISTEMA NERVOSO CENTRAL DE UM CÃO COM ANGIOPATIA AMILOIDE CEREBRAL: RELATO DE CASO................................................. 14

2.1 INTRODUÇÃO

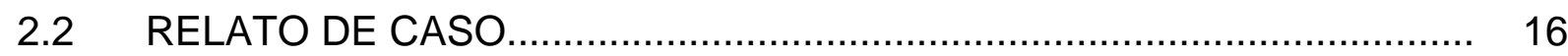

2.3 DISCUSSÃO E CONCLUSÕES......................................................... 22

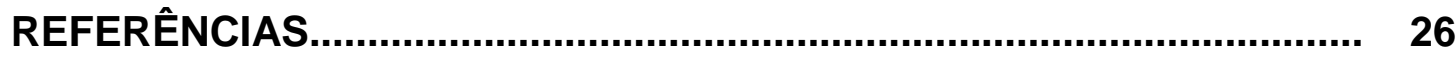

3 AVALIAÇÃO DA DEPOSIÇÃO DE BETA-AMILOIDE NO ENCÉFALO DE CÃES IDOSOS DE DIFERENTES RAÇAS................................ 31

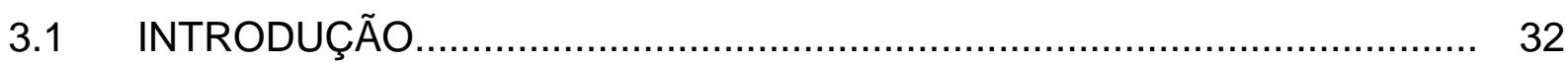

3.2 MATERIAL E MÉTODOS................................................................. 34

3.2.1 Seleção dos casos........................................................................... 34

3.2.2 Coleta das amostras...................................................................... 34

3.2.3 Avaliação histológica................................................................... 35

3.2.4 Imuno-histoquímica....................................................................... 35

3.2.5 Análise morfométrica de A $\beta$ e GFAP .............................................. 36

3.2.6 Análise estatística.......................................................................... 38

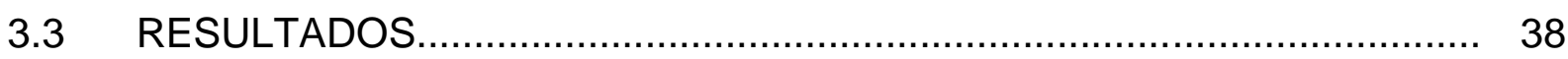

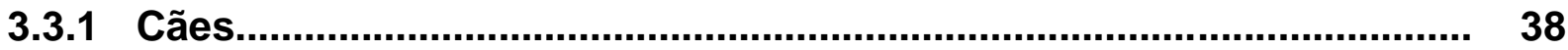

3.3.2 Análises macroscópica e histológica................................................... 40

3.3.3 Análise imuno-histoquímica.......................................................... 43

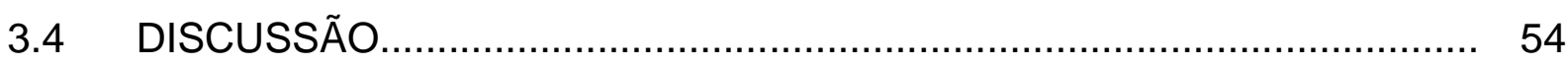

REFERÊNCIAS................................................................... 59

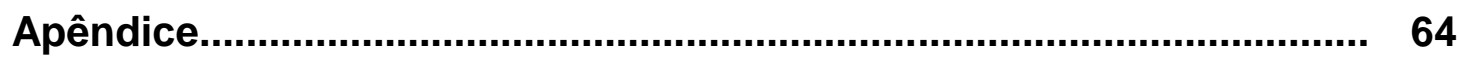




\section{INTRODUÇÃO GERAL}

O presente trabalho compreende o estudo das lesões do sistema nervoso central (SNC) em cães senis, abordando suas características histológicas e imunohistoquímicas, com ênfase na deposição da proteína $\beta$-amiloide $(A \beta)$ no neurópilo e vasos do encéfalo. Portanto, o presente trabalho será divido e apresentado na forma de dois artigos científicos.

Primeiramente, no capítulo 2, será apresentado um artigo científico, intitulado "Múltiplos infartos e hemorragias no sistema nervoso central de um cão com angiopatia amiloide: relato de caso". Este trabalho teve como objetivo relatar um caso apresentando doença vascular encefálica concomitante a áreas de infarto agudas, sub-agudas e crônicas, com áreas de hemorragia e deposição de proteína precursora amiloide nos vasos do encéfalo, caracterizando a angiopatia amiloide cerebral (CAA), em um cão de 16 anos de idade. Além disso, o presente relato objetivou discutir a relação entre as doenças, já que em humanos, a doença de Alzheimer e a angiopatia amiloide cerebral são fortemente correlacionadas com doença vascular encefálica. Este artigo foi publicado no periódico BMC Veterinary Research 2018 (14:370), e o mesmo será aqui apresentado integralmente em português, no capítulo 2, e na secção Apêndice, da forma como foi publicado, em inglês.

O segundo trabalho resulta de um estudo retrospectivo da caracterização histológica e imuno-histoquímica de alterações senis em cães, abordando principalmente a deposição de $A \beta$, no encéfalo de cães senis de diferenças raças. Este artigo será submetido ao periódico Neurobiology of Aging e é intitulado "Avaliação da deposição de beta-amiloide no encéfalo de cães idosos de diferentes raças". O objetivo principal deste trabalho foi caracterizar a deposição de $\beta$-amiloide no neurópilo e vasos do encéfalo de cães senis, bem como sua distribuição em diferentes áreas do encéfalo e correlação com idade e porte do animal. Além disso, também foi avaliado se há associação entre alterações vasculares, tais como microhemorragias perivasculares no encéfalo e a deposição de $A \beta$ nos vasos sob a forma de CAA. 
Múltiplos infartos e hemorragias no sistema nervoso central de um cão com angiopatia amiloide cerebral: relato de caso 


\section{MÚLTIPLOS INFARTOS E HEMORRAGIAS NO SISTEMA NERVOSO CENTRAL DE UM CÃO COM ANGIOPATIA AMILOIDE CEREBRAL: RELATO DE CASO}

No presente capítulo é apresentado um artigo que foi publicado no periódico BMC Veterinary Research, 2018 (14:370).

\section{RESUMO}

Introdução: Cães senis podem apresentar acúmulo da proteína $A \beta(A \beta)$ no encéfalo e quando a mesma acomete a parede dos vasos a doença é denominada angiopatia amiloide cerebral (CAA). Em humanos, a doença de Alzheimer e a CAA são fortemente correlacionadas com doença vascular encefálica (CVD), porém essa associação ainda não foi bem estudada em cães. $O$ presente relato ressalta as características patológicas e clínicas de um caso de CVD e acúmulo de proteína precursora amiloide (APP) concomitantes no encéfalo de um cão.

Apresentação do caso: Uma fêmea da raça Poodle Standard de 16 anos de idade, com histórico de déficits cognitivos por um ano, apresentou quadro agudo de déficit de reação postural dos membros do lado direito, andar em círculos, lateralização da cabeça para o lado esquerdo, nistagmo posicional e ataxia. Devido ao prognóstico desfavorável, o animal foi eutanasiado e a avaliação patológica do encéfalo revelou uma área de infarto lacunar no tálamo que se estendia para o colículo rostral. Outros achados incluíram áreas subagudas e crônicas de isquemia ao longo do encéfalo, além de áreas de hemorragia na medula oblonga. A imunomarcação revelou deposito de APP nos vasos do parênquima dos córtex frontal, temporal e occipital, hipocampo, diencéfalo, mesencéfalo e mielencéfalo, além das paredes dos vasos das meninges. A imunomarcação da proteína glial fibrilar ácida (GFAP) mostrou marcada astrocitose ao redor da área aguda de infarto e nas áreas crônicas de 
isquemia. A avaliação histológica do encéfalo juntamente com a marcação imunohistoquímica evidenciaram a presença de CDV concomitante ao acúmulo de APP no neurópilo e na parede dos vasos.

Conclusão: O presente relato demonstra que o acúmulo de APP no encéfalo pode ocorrer concomitantemente a um quadro severo de CDV em cães. São necessários mais estudos a fim de esclarecer se o CDV está associado ao acúmulo de A $\beta$ no encéfalo de cães.

Palavras-chave: amiloide, CAA, canino, angiopatia congofílica, isquemia, acidente vascular encefálico.

\subsection{INTRODUÇÃO}

A doença vascular encefálica (CVD), definida como qualquer anormalidade do sistema nervoso central (SNC) que resulte de um processo patológico com comprometimento do suprimento sanguíneo (KALIMO; KASTE; HALTIA, 2002), é uma causa importante de incapacitação em humanos. Apesar de ser relativamente rara, a CVD é reconhecida como uma causa de disfunção neurológica em cães e gatos e pode ser classificada como isquêmica ou hemorrágica (GAROSI, 2010; BOUDREAU, 2018).

Oclusão vascular por tromboembolismo resultando em isquemia e ruptura vascular causando hemorragia são as principais consequências diretas da CVD em cães e gatos (BOUDREAU, 2018). Hipertensão crônica, que resulta em aterosclerose e lipo-hialinose nas pequenas artérias penetrantes do encéfalo (GAROSI et al., 2005; WESSMANN; CHANDLER; GAROSI, 2009), pode ser umas das principais causas subjacentes para a predisposição de cães para a CVD. Outras condições que podem predispor o animal ao quadro incluem neoplasia, sepse, hipotireoidismo, parasitas, malformação vascular e coagulopatia (WESSMANN; CHANDLER; GAROSI, 2009).

A angiopatia amiloide cerebral (CAA), caracterizada pela deposição de peptídeo $\beta$-amiloide $(A \beta)$ nos vasos do parênquima e leptomeninges, é uma doença comum em pessoas idosas, e está associado à doença de Alzheimer (AD) 
(ATTEMS, 2005). Nos cães, uma condição semelhante a AD, que é caracterizada pelo acúmulo de placas senis compostas tanto pela proteína precursora amiloide (APP) quanto pelo $A \beta$, tem sido descrita (UCHIDA et al., 1990, 1992; CUMMINGS et al., 1996; OKUDA et al., 1994; YOSHINO et al., 1996 et al., 2010; YU et al., 2011), assim como o acúmulo de $A \beta$ nas paredes dos vasos (UCHIDA et al., 1990, 1992; OKUDA et al., 1994). Nos humanos, a CAA tem sido associada às lesões vasculares, como infartos isquêmicos e hemorragias intracerebrais (ATTEMS, 2005). Hemorragias intracerebrais também têm sido associadas à CAA em cães (UCHIDA et al., 1990).

Apesar de infartos, hemorragias e perda de substância branca cerebral serem associados à CAA em humanos (ATTEMS, 2005), poucos estudos relatam a ocorrência de infarto cerebral concomitante a hemorragias em cães com CAA. $O$ objetivo do presente estudo foi descrever os aspectos clínicos e patológicos dos infartos e hemorragias envolvendo o SNC de um cão com deposição de APP nas paredes dos vasos.

\subsection{RELATO DE CASO}

Uma fêmea da raça Poodle Standard foi atendida em uma clínica veterinária privada. O tutor relatava diversas alterações no estado mental do animal, que se iniciaram um ano antes da data do exame clínico. Tais alterações incluíam confusão mental e redução da consciência, dificuldade de reconhecimento dos membros da família e esquecimento de habilidades previamente aprendidas. Dois dias após o primeiro atendimento, o animal apresentou um episódio de convulsão tônico-clônica generalizada. Após esse episódio, o animal começou a apresentar hiporexia e letargia, além de andar em círculos e ataxia.

Ao exame neurológico, o animal apresentou alterações no lado direito do corpo caracterizadas por déficit de reação postural, desvio lateral da cabeça e pescoço com inclinação da cabeça para o lado esquerdo, andar em círculos, nistagmo posicional e ataxia. O tutor optou por não realizar o exame de ressonância magnética para definição do diagnóstico.

Os sinais clínicos evoluíram para decúbito lateral e inabilidade em se alimentar sem auxílio, caracterizando um prognóstico ruim. Foi então realizada a eutanásia do animal e o mesmo foi submetido à necropsia no Departamento de 
Patologia Animal da Faculdade de Medicina Veterinária e Zootecnia (FMVZ) da Universidade de São Paulo (USP). O encéfalo foi fixado em formalina tamponada a $10 \%$ e processado através dos métodos rotineiros para histologia. Secções do encéfalo foram coradas com hematoxilina e eosina, além de submetidas à imunohistoquímica (IHQ) para detecção de APP e proteína glial fibrilar ácida (GFAP). Para a realização da técnica de $\mathrm{IHQ}$, as lâminas contendo as secções do SNC foram inicialmente submetidas à recuperação antigênica com o uso de tampão citrato $\mathrm{pH}$ 6,0 e logo após incubadas com anticorpos primários anti-APP (Millipore, Darmstadt, Alemanha) e anti-GFAP (Dako, Agilent, Santa Clara, California, EUA), diluídos à 1:200 e 1:14000, respectivamente. A ligação antígeno-anticorpo foi visualizada utilizando o kit EnVision FLEX System (Dako, Agilent, Santa Clara, California, EUA), de acordo com as instruções do fabricante. Como controle positivo para a marcação de APP, foi utilizado um encéfalo de um cão acometido por trauma cranioencefálico com degeneração axonal. O encéfalo de um cão jovem sem lesões significantes detectadas ao exame histológico foi utilizado para controle negativo para a imunomarcação para APP.

Macroscopicamente, os ventrículos laterais se apresentavam discretamente distendidos, com achatamento dos giros e alargamento dos sulcos.

Histologicamente, os vasos sanguíneos intraparenquimatosos e das leptomeninges de diversas áreas do SNC, abrangendo do mielencéfalo até o córtex cerebral, se encontravam de discretamente a acentuadamente espessados por material hialino e acelular. Na região paramediana direita, se estendendo do tálamo, no nível da junção de diencéfalo e mesencéfalo, ao núcleo oculomotor, no nível do colículo rostral, havia uma área lacunar localmente extensa, bem demarcada, com perda marcante da coloração do neurópilo com necrose coagulativa cercada por uma borda de espongiose severa (Figura 1A). Dentro da área de necrose, os neurônios apresentavam núcleos picnóticos e citoplasma hipereosinofílico (necrose neuronal). Havia também necrose e degeneração das células da glia e das células endoteliais, caracterizadas por núcleos picnóticos e cariorréticos (Figura 1B). Os compartimentos perivasculares dos vasos adjacentes se encontravam infiltrados por um pequeno número de histiócitos (Figura 1C). Na área de espongiose havia um grande número de axônios tumefeitos formando esferoides axonais (degeneração axonal). A imunomarcação para GFAP mostrou um aumento no número, espessura e complexidade do processo astrocitários (astrogliose) em torno da lesão necrótica 
(Figura 1D). Os processos astrocitários não estavam evidentes e o GFAP foi pouco detectado nos astrócitos degenerados dentro da área necrótica. Tais achados são compatíveis com lesão de isquemia ou infarto agudo, apresentando inflamação discreta e gliose reativa em estágio inicial.

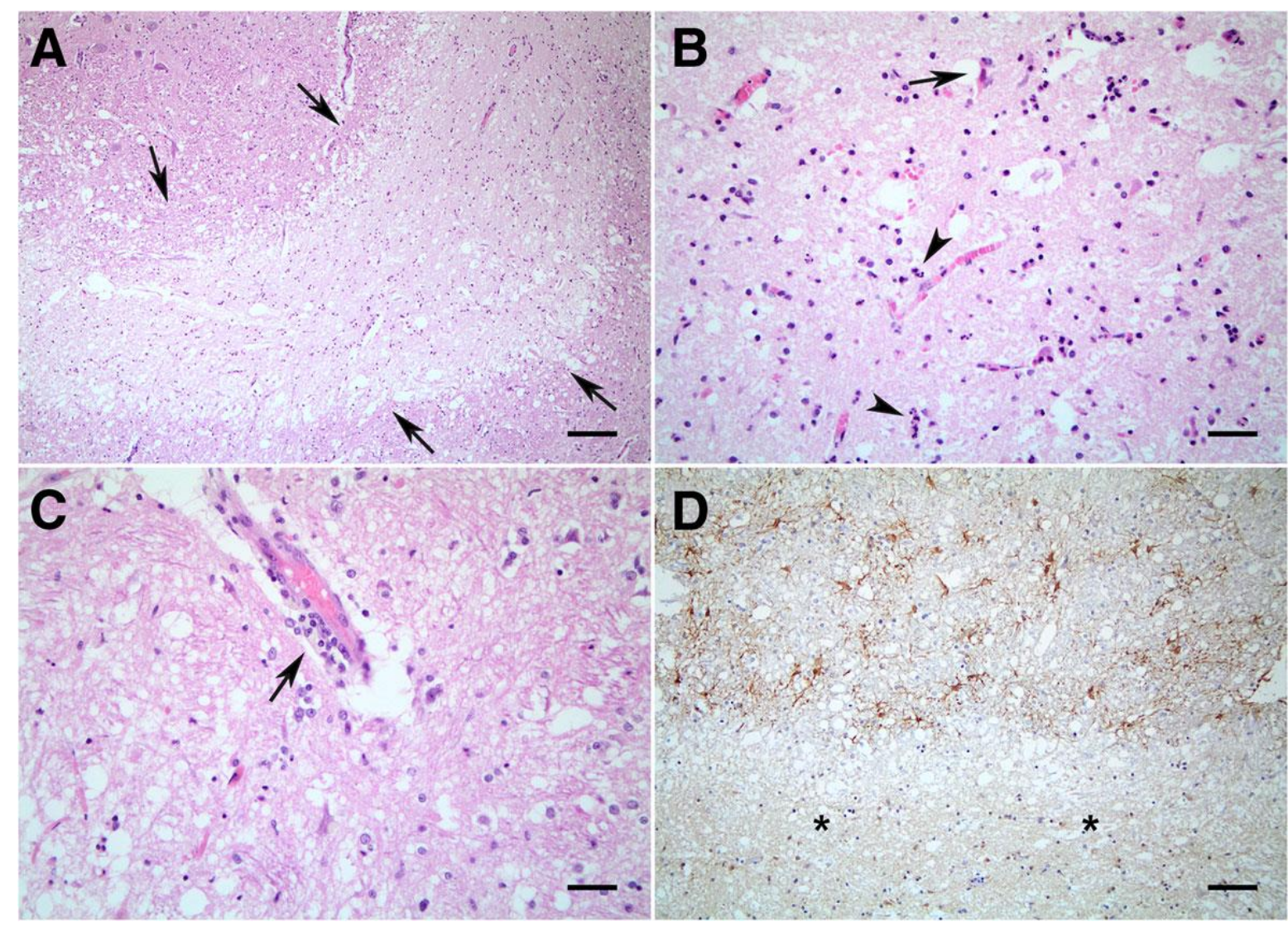

FIGURA 1 - Angiopatia amiloide cerebral em um cão: lesões no sistema nervoso central. (A-C): coloração com hematoxilina e eosina. (A) Ao nível do núcleo oculomotor, uma área lacunar bem delimitada de isquemia aguda com necrose coagulativa, cercada por margem de espongiose severa (setas) foi visualizada. (B) Na área do infarto, havia necrose neuronal (seta), além de necrose e degeneração de células da glia (cabeças das setas). (C) Manguito perivascular com pequeno número de histiócitos foi detectado ao redor dos vasos da área do infarto. (D) Imunomarcação para GFAP mostrou severa astrogliose (coloração marrom) cercando a área de necrose (asteriscos), na qual os processos astrocitários não se encontravam evidentes. Barras de escala: A - $200 \mu \mathrm{m}, \mathrm{B}-70 \mu \mathrm{m}, \mathrm{C}-$ $50 \mu \mathrm{m}, \mathrm{D}-100 \mu \mathrm{m}$. Fonte: (RODRIGUES, L.L, 2019).

Foram visualizadas áreas multifocais de infarto subagudo no cerebelo, envolvendo principalmente a camada granulosa e substância branca adjacente (Figura 2A). Tais áreas foram caraterizadas por um grande número de células granulosas com núcleos picnóticos e cariorréticos, liquefação do neurópilo, em meio número moderado de macrófagos espumosos (células Gitter) e esferoides axonais 
(Figura 2B). Estas áreas se encontravam cercadas por um número moderado de vasos sanguíneos neoformados com hipertrofia de células endoteliais (neovascularização) com áreas adjacentes de hemorragia e manguitos perivasculares discretos contendo histiócitos. Astrogliose proeminente, demostrada pela imunomarcação com GFAP, envolvendo também a glia de Bergman, foram visualizados na periferia destas áreas necróticas (Figura 2C).

Áreas lacunares crônicas de isquemia também se encontravam presentes no telencéfalo ao nível dos núcleos da base e hipocampo. Tais áreas se apresentavam pálidas, bem demarcadas, com perda neuronal e com marcada proliferação de capilares e hipertrofia de células endoteliais. Além disso, havia também discreta a moderada espongiose com aumento no número de células da glia (gliose), incluindo número moderado de células com citoplasma eosinofílico abundante e núcleo excêntrico (gemistócitos). Raros manguitos perivasculares com pequeno número de histiócitos foram visualizados. Nestas áreas havia marcante aumento do número de astrócitos (astrocitose) e astrogliose, como demonstrado pela imunomarcação por GFAP (Figura 2D).

Adicionalmente às áreas de isquemia ou infarto, da medula oblonga até o nível do óbex, foram visualizadas áreas multifocais de hemorragia na formação reticular e nos núcleos da base (Figura 3). A substância branca de diversas áreas, incluindo telencéfalo até o mielencéfalo, se encontravam degenerados em diferentes graus. 


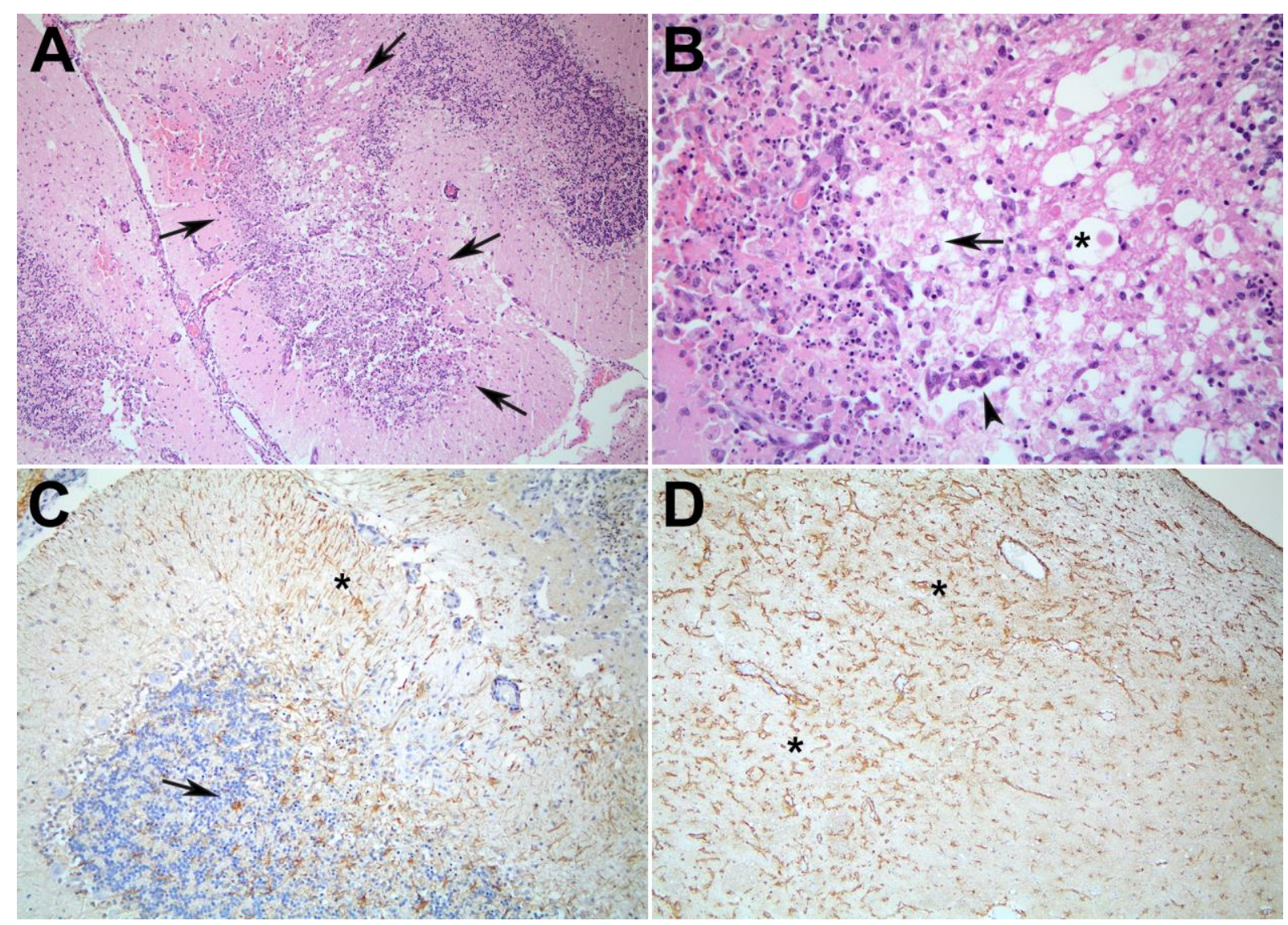

FIGURA 2 - Angiopatia amiloide cerebral em um cão: lesões no sistema nervoso central. (A-B): coloração com hematoxilina e eosina. (A) No cerebelo, uma área de infarto lacunar subaguda foi visualizada, acometendo a camada granular e substância branca adjacente (setas). (B) O infarto subagudo era caracterizado por necrose liquefativa e coagulativa com células Gitter (seta), vasos neoformados (cabeças das setas) e esferoides axonais (asteriscos). (C) A imunomarcação com GFAP demonstrou astrogliose proeminente (seta), envolvendo também a glia de Bergmann (asterisco) (D) Nas áreas de isquemia crônica, havia marcado aumento do número de astrócitos (astrocitose) e astrogliose, demonstrados pela imunomarcação por GFAP (asteriscos). Barras de escala: A, C, D - $200 \mu \mathrm{m}, \mathrm{B}-50 \mu \mathrm{m}$. Fonte: (RODRIGUES, L.L, 2019). 


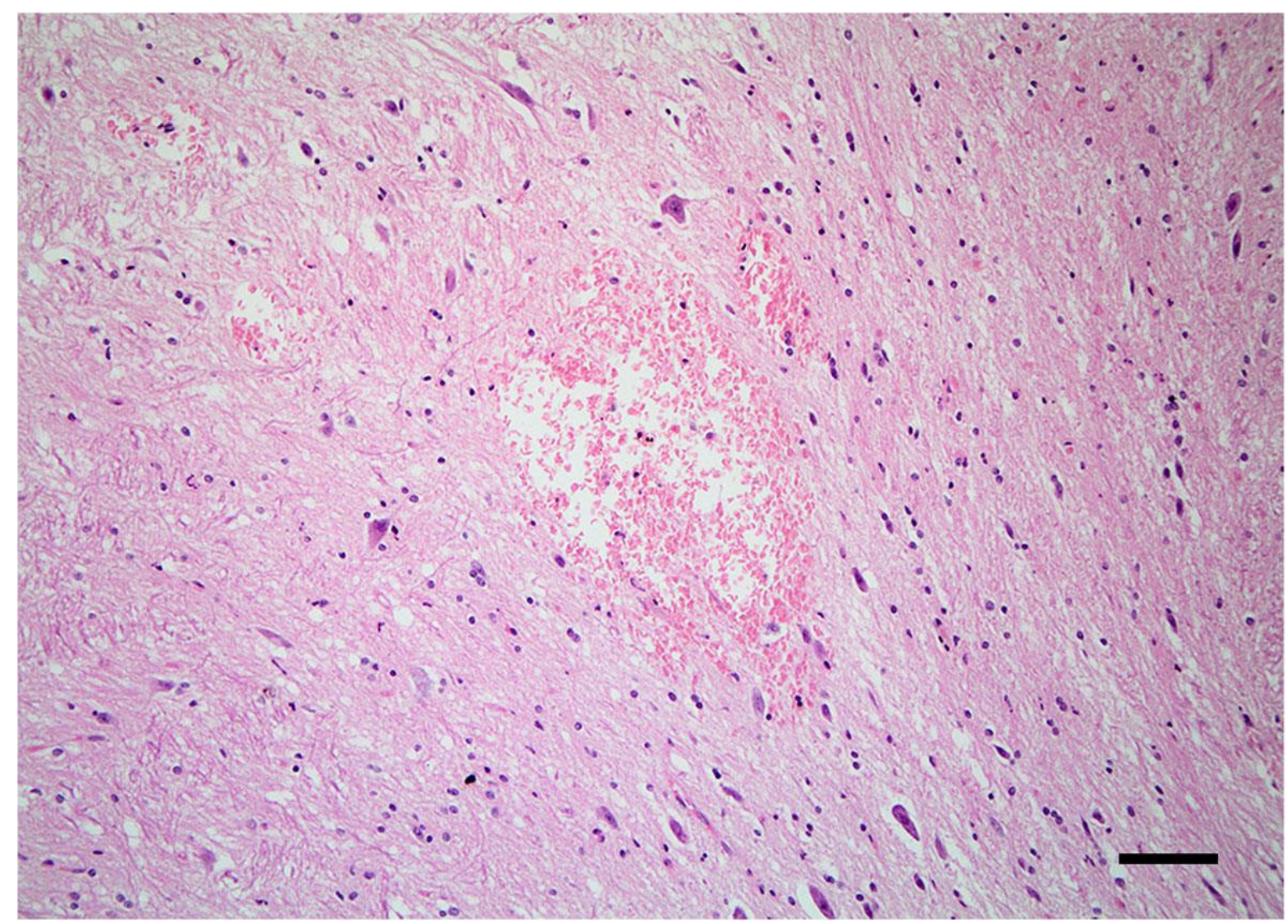

FIGURA 3 - Angiopatia amiloide cerebral em um cão: lesões no sistema nervoso central: coloração com hematoxilina e eosina. Hemorragias multifocais na medula oblonga ao nível do obex. Barra de escala: $100 \mu \mathrm{m}$. Fonte: (RODRIGUES, L.L, 2019).

A imunomarcação para APP foi visualizada mais frequentemente nas paredes de vasos sanguíneos intraparenquimatosos (Figura 4A), e ocasionalmente acometendo os vasos das leptomeninges. $A$ intensidade da imunomarcação por APP variou de discreta a severa, de acordo com Attems (2005). A APP afetou vasos sanguíneos de diferentes áreas do SNC, mas tinha uma distribuição irregular, caracterizada por áreas positivas para a marcação de APP, adjacentes a áreas negativas. Os lobos frontal e temporal foram mais afetados quando comparados ao lobo occipital. Outras áreas afetadas incluem o hipocampo, o diencéfalo, o mesencéfalo e o mielencéfalo. $O$ cerebelo foi menos afetado. Além disso, raros vasos com alterações disóricas foram observados, caracterizando a disseminação de APP dos vasos para o neurópilo adjacente (Figura 4B). Importante salientar que grande número de vasos hialinizados não foram imunomarcados para APP, especialmente os que possuíam paredes mais espessas. Na periferia do infarto agudo, axônios tumefeitos e degenerados foram imunomarcados para APP (Figura $4 \mathrm{C})$. 
Ao nível da comissura rostral (núcleos da base) e tálamo havia áreas localmente extensas onde áreas multifocais marcadas para APP no neurópilo foi visualizada. Nestas áreas, dois tipos de marcação para APP foram detectadas. Pequenas áreas marcadas, de até $25 \mu \mathrm{m}$ de diâmetro, de formato circular, com área central apresentando marcação densa e escura (Figura 4D) foram visualizadas, além de outras áreas marcadas onde a área central escurecida não se encontrava presente (Figura 4E) (GARCIA-MARIN et al., 2009).

O encéfalo de um cão jovem usado como controle negativo não exibiu imunomarcação para APP tanto no neurópilo como nos vasos do SNC (Figura 4F).

\subsection{DISCUSSÃO E CONCLUSÕES}

O diagnóstico da CAA foi baseado nas alterações histológicas observadas nos vasos sanguíneos, e na demonstração da presença de APP nas paredes destes vasos pela IHQ. Em cães, similar ao que ocorre em humanos, o $A \beta$ é derivado da APP (SU; COTMAN; WHITE, 1993). Deste modo, no presente estudo, a detecção da APP sugere fortemente uma doença vascular encefálica em curso associada à deposição de $A \beta$. Além das paredes dos vasos sanguíneos, a imunomarcação da APP também foi visualizada em algumas áreas do neuroparênquima do SNC do cão do presente relato. Além disso, este cão apresentava lesões histológicas de injúria vascular, tais como isquemia ou infarto e hemorragias. 


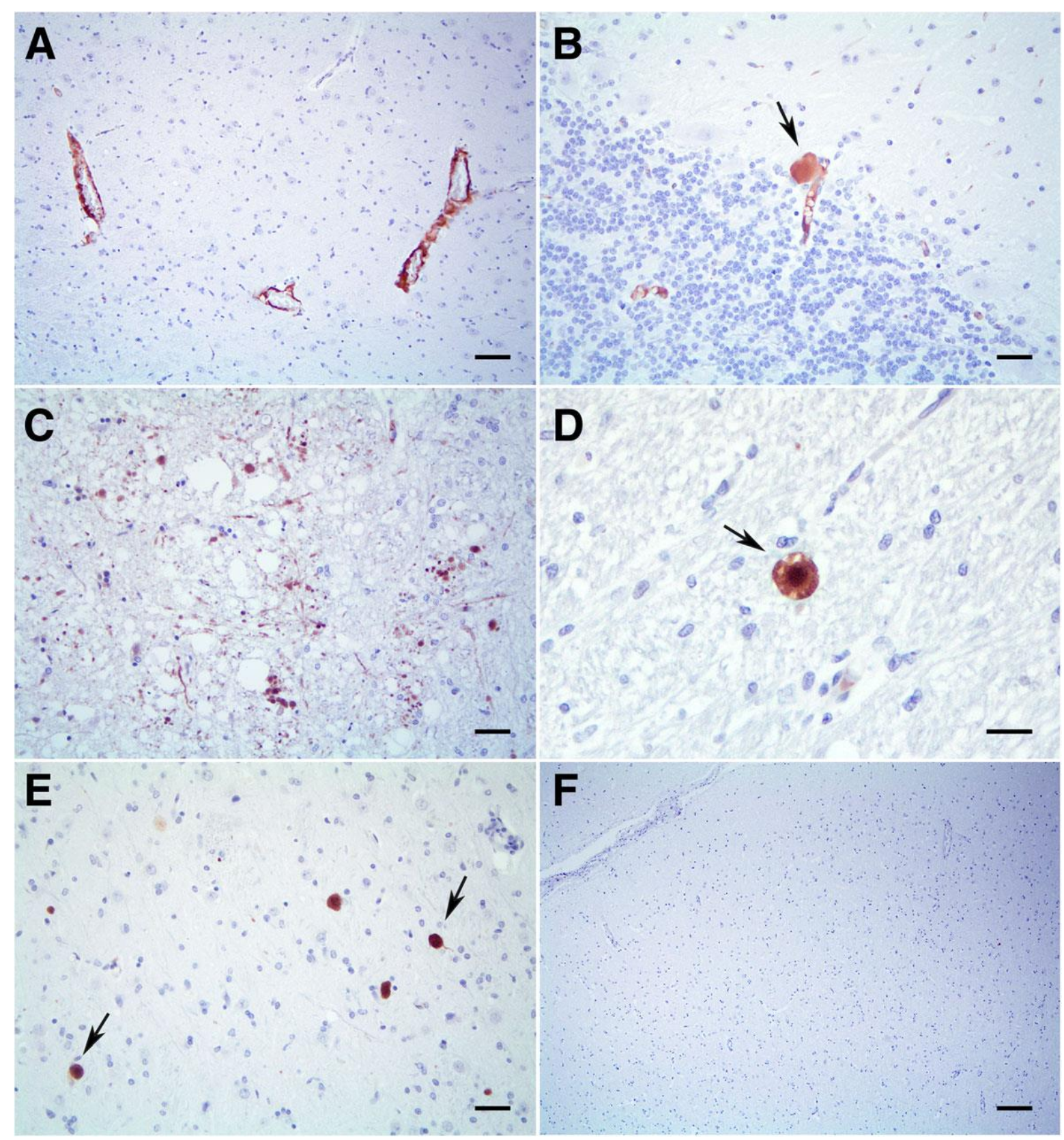

FIGURA 4 - Angiopatia amiloide cerebral em um cão: detecção da proteína precursora amiloide (APP). (A) A parede dos vasos sanguíneos intraparenquimatosos forma fortemente imunomarcadas para APP (coloração marrom). (B) Extravasamento da APP dos vasos sanguíneos para o neurópilo adjacente foi visualizado no cerebelo. (C) Axônios tumefeitos e degenerados foram imunomarcados para APP na periferia da área do infarto agudo. (D) Áreas pequenas, de até $25 \mu \mathrm{m}$ de diâmetro, imunomarcadas para APP contendo uma área central com marcação densa e escura foram detectadas. (E) Outras áreas imunomarcadas para APP, de formato arredondado e sem a área central com marcação densa, também foram visualizadas. ( $F) O$ encéfalo de um cão controle não apresentou imunomarcação para APP. Barras de escala: (A) - $70 \mu \mathrm{m},(B),(C),(E)-50 \mu \mathrm{m},(\mathrm{D})-50$ $\mu \mathrm{m},(\mathrm{F})-200 \mu \mathrm{m}$. Fonte: (RODRIGUES, L.L, 2019). 
Diversas alterações neurológicas como as observadas em humanos têm sido descritas no SNC de cães senis (revisado por VITE; HEAD, 2014). Tais alterações incluem depósitos de Aß, CAA, doenças vasculares e infartos (VITE; HEAD, 2014), além de outras. O exame post-mortem da cão de 16 anos relatado no presente estudo com sinais clínicos neurológicos agudos antes de sua morte revelou que o animal possuía CAA severa, além de depósitos de $A \beta$ no neurópilo, o que também ocorre nos pacientes acometidos pela AD. Em humanos, tais alterações estão correlacionadas entre si, sendo a prevalência de CAA na AD superior a $70 \%$ (ATTEMS, 2005). A severidade da CAA tem sido correlacionada à progressão da $A D$ (ATTEMS; JELLINGER; LINTNER, 2005). Em cães, uma condição semelhante à AD em humanos, com formação de placas por depósito de $A \beta$ foi descrita (UCHIDA et al., 1990, 1992; CUMMINGS et al., 1996; OKUDA et al., 1994; YOSHINO et al., 1996; YU et al., 2011). A deposição de $A \beta$ nas paredes dos vasos intraparenquimatosos e das leptomeninges, resultando em CAA, também foi reportada em cães (UCHIDA et al., 1990, 1992; YOSHINO et al., 1996).

Além da CAA e deposição de $A \beta$ no parênquima do SNC, o cão do presente relato também possuía diversas áreas de isquemia/infarto e hemorragias no encéfalo. Em humanos, a CAA tem sido associada com tais desordens vasculares (ATTEMS, 2005). Na CAA, elementos elásticos e musculatura lisa são substituídos por deposição de $A \beta$, o que pode predispor a aneurismas e consequentes hemorragias intracerebrais (ATTEMS, 2005). Em cães, hemorragias intracerebrais têm sido associadas à CAA (UCHIDA et al., 1990).

No presente estudo, as áreas de infarto isquêmico encefálico possuíam distribuição lacunar, demonstrando que as artérias pequenas e penetrantes do parênquima foram provavelmente os vasos mais afetados. Em um estudo prévio, a causa dos infartos lacunares em cães não pôde ser determinada (GONÇALVES et al., 2011). Infartos isquêmicos cerebrais têm sido observados em pacientes com CAA, o que pode representar um fator de risco para infartos cerebrais em pessoas senis (CADAVID et al., 2000). Apesar do exato mecanismo patogênico do infarto isquêmico associado à CAA ainda ser desconhecido (ATTEMS, 2005), a deposição de $A \beta$ na parede dos vasos pode induzir perda da resposta vascular a estímulos vasodilatadores, além de inibição da formação de circulação colateral dos tecidos isquêmicos, resultando em isquemia mais severa (HSIAO et al., 2018). No caso relatado, vasos intraparenquimatosos e das leptomeninges espessados e 
hialinizados não imunomarcados para APP foram visualizados. Histologicamente, tais vasos se assemelham aos que são observados em humanos idosos acometidos por demência vascular (ROMÁN; KALARIA, 2006). Apesar da CAA poder contribuir para o desenvolvimento de injuria isquêmica no encéfalo do caso descrito, não podemos descartar outros processos patológicos associados aos vasos causando tal alteração. A sobreposição de $A D$ e lesões vasculares encefálicas estão se tornando cada vez mais evidentes (ATTEMS; JELLINGER, 2014). Alterações vasculares encefálicas podem ser encontradas em uma proporção significativa dos pacientes com AD (ROMÁN; KALARIA, 2006). Lesões vasculares encefálicas e AD podem coexistir em estágios iniciais do déficit cognitivo e podem influenciar sua severidade e progressão, tornando o diagnóstico desafiador até mesmo para os neuropatologistas (ATTEMS; JELLINGER, 2014).

O cão apresentado no relato apresentava déficits cognitivos com evolução de um ano, tais como dificuldade de reconhecer os membros da família e perda de habilidades previamente aprendidas. Áreas isquêmicas múltiplas de evolução aguda a crônica no encéfalo desse cão, além de reatividade astrocitária evidente em tais áreas, demonstraram que o cão descrito no relato sofria de uma doença cerebral vascular em curso. É mais provável que os déficits cognitivos apresentados pelo animal tenham sido causados pelo depósito de $A \beta$ no encéfalo e pela perda neuronal, do que pelas múltiplas áreas de isquemia (VITE; HEAD, 2014). Os sinais clínicos apresentados pelo animal durante o exame neurológico, tais como reação de déficit postural ipsilateral, andar em círculos ipsilateral, lateralização da cabeça contralateral à lesão, nistagmo posicional e ataxia, estão provavelmente relacionados ao infarto agudo isquêmico que se estendia do tálamo ao diencéfalo e junção com mesencéfalo. Sinais clínicos similares foram observados em cães com infarto em mesencéfalo e tálamo (GONÇALVES et al., 2011).

Em conclusão, esse relato de caso mostra um caso de doença neurodegenerativa caracterizada pela deposição de APP, o qual é um precursor de $A \beta$, no neurópilo e vasos, concomitante à doença vascular encefálica em um cão senil. Mais estudos são necessários para elucidar a relação entre a doença vascular e o acúmulo de $A \beta$ no encéfalo de cães. 


\section{REFERÊNCIAS}

ATTEMS, J. Sporadic cerebral amyloid angiopathy: pathology, clinical implications, and possible pathomechanisms. Acta Neuropathologica, v. 110, n. 4, p. 345-359, 2005. Disponível em: < https://www.ncbi.nlm.nih.gov/pubmed/16170565>. Acesso em: 11/09/2018.

ATTEMS, J.; JELLINGER, K. A. The overlap between vascular disease and Alzheimer's disease - lessons from pathology. BMC Medicine, v. 12, n. 1, p. 1-12, 2014. Disponível em:< https://www.ncbi.nlm.nih.gov/pubmed/25385447>. Acesso em: 11/09/2018.

ATTEMS, J.; JELLINGER, K. A.; LINTNER, F. Alzheimer's disease pathology influences severity and topographical distribution of cerebral amyloid angiopathy. Acta Neuropathologica, v. 110, n. 3, p. 222-231, 2005. Disponível em :<https://www.ncbi.nlm.nih.gov/pubmed/16133541>. Acesso em: 11/09/2018.

BOUDREAU, C. E. An Update on Cerebrovascular Disease in Dogs and Cats. Veterinary Clinics of North America - Small Animal Practice, v. 48, n. 1, p. 4562, 2018. Disponível em: <https://doi.org/10.1016/j.cvsm.2017.08.009>. Acesso em: 10/09/2018.

CUMMINGS, B. J.; HEAD, E.; RUEHL, W.; MILGRAM, N. W.; COTMAN, C. W. The canine as an animal model of human aging and dementia. Neurobiology of Aging, v. $17, \quad$ n. 2 , p. 259-268, 1996. Disponível em: <https://www.ncbi.nlm.nih.gov/pubmed/8744407>. Acesso em: 14/09/2018.

CADAVID, D.; MENA, H.; KOELLER, K.; FROMMELT, R. A.;. Cerebral beta amyloid angiopathy is a risk factor for cerebral ischemic infarction. A case control study in human brain biopsies. Journal of neuropathology and experimental neurology, $v$. 59, n. 9 , p. $768-73$, 2000. Disponível em: < https://www.ncbi.nlm.nih.gov/pubmed/11005257->. Acesso em: 14/09/2018. 
GAROSI, L.; McCONNEL, S. R.; PLATT, S. R. BARONE, J. C.; DELAHUNTA, A.; SCHATZBERG. S. J. Results of Diagnostic Investigations and Long-Term Outcome of 33 Dogs with Brain Infarction (2000-2004). Journal of Veterinary Internal Medicine, $\quad$ p. $725-731, \quad 2005 . \quad$ Disponível em:< https://www.ncbi.nlm.nih.gov/pubmed/16231718>. Acesso em: 05/09/2018.

GAROSI, L. S. Cerebrovascular Disease in Dogs and Cats. Veterinary Clinics of North America - Small Animal Practice, v. 40, n. 1, p. 65-79, 2010. Disponível em: <http://dx.doi.org/10.1016/j.cvsm.2009.09.001>. Acesso em: 05/08/2018.

GARCIA-MARIN, V.; BLAZQUEZ-LLORCA, L.; RODRIGUEZ, J.; R.; BOLUDA, S.; MUNTANE, G.; FERRER, I.; DEFELIPE, J.. Diminished perisomatic GABAergic terminals on cortical neurons adjacent to amyloid plaques. Frontiers in Neuroanatomy, v. 3 , n. 28, p. 1-18, 2009. Disponível em:< https://www.ncbi.nlm.nih.gov/pmc/articles/PMC2784678/>. Acesso em: 27/08/2018.

GONÇALVES, R.; CARRERA, I.; GAROSI, L.; SMITH, P. M.; McCONNELL, J.; PENDERIS, J.. Clinical and topographic magnetic resonance imaging characteristics of suspected thalamic infarcts in 16 dogs. Veterinary Journal, v. 188, n. 1, p. 39-43, 2011. Disponível em: < https://www.ncbi.nlm.nih.gov/pubmed/20456988>. Acesso em: $27 / 08 / 2018$.

ZHANG, F.; ECKMAN, C.; HSIAO, K.. K.; IADECOLA, C. Increased Susceptibility to Ischemic Brain Damage in Transgenic Mice Overexpressing the Amyloid Precursor Protein. The Journal of Neuroscience, v. 17, n. 20, p. 7655-7661, 1997. Disponível em: < https://www.ncbi.nlm.nih.gov/pubmed/9315887>. Acesso em: 27/08/2018.

KALIMO, H; KASTE, M; HALTIA, M. Vascular diseases. In: GRAHAM DI, L. P. (Ed.). Greenfield's neuropathology. 7th. ed., p. 233-280.

OKUDA, R.; UCHIDA, S.; TATEYAMA, S.; YAMAGUCHI, R.; NAKAYAMA, H; GOTO, $\mathrm{N}$. The distribution of amyloid beta precursor protein in canine brain. Acta Neuropathologica, $\quad$ v. $87, \quad$ n. 2, p. 161-167. Disponível em: <https://link.springer.com/article/10.1007/BF00296186>. Acesso em: 26/08/2018. 
ROMÁN, G. C.; KALARIA, R. N. Vascular determinants of cholinergic deficits in Alzheimer disease and vascular dementia. Neurobiology of Aging, v. 27, n. 12, p. 1769-1785, 2006. Disponível em: https://www.ncbi.nlm.nih.gov/pubmed/16300856>. Acesso em: 10/09/2018.

CUMMINGS, C. J.; SU, J. H.; COTMAN, C. W.; WHITE, R; RUSSELL, M. J.. Betaamyloid accumulation in aged canine brain: a model of early plaque formation in Alzheimer's disease. Frontiers in Neuroanatomy, v. 14, n. 16, p. 547-560, 1993. Disponível em: <https://www.ncbi.nlm.nih.gov/pubmed/8295657>. Acesso em 10/09/2018.

YOSHINO, T.; UCHIDA, K. TATEYAMA, S.; YAMAGUCHI, R.; NAKAYAMA. $H$; GOTO, N. A retrospective study of canine senile plaques and cerebral amyloid angiopathy. Veterinary Pathology, v. 33, n. 2, p. 230-234, 1996. Disponível em: < https://www.ncbi.nlm.nih.gov/pubmed/8801718>. Acesso em 10/09/2018.

UCHIDA, K.; MIYAUCHI, Y.; NAKAYAMA, H.; GOTO, N. Amyloid angiopathy with cerebral hemorrhage and senile plaque in aged dogs. Nihon juigaku zasshi. The Japanese journal of veterinary science, v. 52, n. 3, p. 605-11, 1990. Disponível em: < http://europepmc.org/abstract/med/2385040>. Acesso em:<12/08/2018.

UCHIDA, K.; TANI, Y.; UETSUKA, K.; NAKAYAMA, H.; GOTO, N. Immunohistochemical studies on canine cerebral amyloid angiopathy and senile plaques. The Journal of Veterinary Medical Science, v. 54, n. 4, p. 659-667, 1992. Disponível em: <https://www.semanticscholar.org/paper/lmmunohistochemicalstudies-on-canine-cerebral-and-Uchida-

Tani/2aa5ca61dfd940d2449953b5b22970949aa813b8 >. Acesso em 12/08/2018.

VITE, C. H.; HEAD, E. Aging in the Canine and Feline Brain. Veterinary Clinics of North America: Small Animal Practice, v. 44, n. 6, p. 1113-1129, 2014. Disponível em: <https://www.ncbi.nlm.nih.gov/pubmed/25441628>. Acesso em 12/08/2018. 
WESSMANN, A.; CHANDLER, K.; GAROSI, L. Ischaemic and haemorrhagic stroke in the dog. Veterinary Journal, v. 180, n. 3, p. 290-303, 2009. Disponível em: < https://www.ncbi.nlm.nih.gov/pubmed/18579421 >. Acesso em 12/08/2018.

YU, C. H. et al. Histopathological and Immunohistochemical Comparison of the Brain of Human Patients with Alzheimer's Disease and the Brain of Aged Dogs with Cognitive Dysfunction. Journal of Comparative Pathology, v. 145, n. 1, p. 45-58, 2011. Disponível em: <https://www.ncbi.nlm.nih.gov/pubmed/21256508>.Acesso em: 12/08/2018. 
Avaliação da deposição de beta-amiloide no encéfalo de cães idosos de diferentes raças 


\section{AVALIAÇÃo dA DEPOSIÇÃO DE BETA-AMILOIDE NO ENCÉFALO DE CÃES IDOSOS DE DIFERENTES RAÇAS}

No presente capítulo é apresentado um artigo que será submetido ao periódico Neurobiology of Aging.

\section{RESUMO}

A espécie canina tem sido utilizada como modelo animal para o estudo das doenças em humanos em que ocorre a deposição de beta-amiloide $(A \beta)$ no encéfalo, tais como a doença de Alzheimer e a angiopatia amiloide cerebral (CAA). Entretanto, muitos aspectos da deposição de $A \beta$ no encéfalo de cães ainda são desconhecidos. O estudo teve como objetivo avaliar a deposição de $A \beta$ em áreas distintas do encéfalo de cães idosos de diferentes raças. A proteína $A \beta$ foi detectada tanto sob a forma de placas senis no neurópilo da substância cinzenta, como na parede de vasos leptomeníngeos e do neurópilo nos cães senis. Considerando toda a população analisada, houve uma correlação positiva entre o aumento da idade e a deposição de $A \beta$ no SNC de cães, tanto sob a forma de placas como na parede dos vasos. Porém não houve correlação entre a área de deposição de $A \beta$ sob a forma de placas e a idade, em cães a partir de oito anos. Diferentemente, na CAA, houve correlação positiva entre a área de deposição de $A \beta$ com o aumento da idade, mesmo no grupo de cães com acima de oito anos de idade. A CAA estava associada à ocorrência de micro-hemorragias perivasculares no encéfalo, sendo que os cães com CAA possuem nove vezes mais chances de apresentarem microhemorragias, quando comparados àqueles que não apresentam CAA. Não houve diferença na área de deposição de $A \beta$ tanto sob a forma de placas, como em vasos, entre os córtices frontal, temporal e occipital. Em conclusão, o presente estudo demonstrou que a deposição de $A \beta$, sob a forma de placas senis ou CAA é extremamente heterogênea em cães de diferentes raças e portes. Apesar de várias características da doença em cães serem semelhantes àquelas em observadas em humanos, a escolha da raça e porte para utilização como modelo animal pode interferir no padrão de deposição de $A \beta$ no encéfalo. 


\subsection{INTRODUÇÃO}

Com o avanço da tecnologia, e aumento dos cuidados com a saúde e nutrição, a expectativa de vida dos humanos e animais têm aumentado nas últimas décadas, assim como a prevalência de doenças associadas ao envelhecimento, como as doenças degenerativas, entre elas as que acometem o sistema nervoso central (SNC) (LANDSBERG et al, 2002).

Diversas lesões encefálicas associadas ao envelhecimento são observadas nos cães. Entre elas, o acúmulo de proteína $\beta$-amiloide $(A \beta)$, na parede dos vasos ou sob a forma de placas senis, além de perda neuronal, atrofia do córtex e astrocitose, com consequente dilatação ventricular e redução do volume cerebral (ROFINA et al., 2004; CHARIDIMOU; GANG; WERRING, 2012; SCHMIDT et al., 2015). Por apresentar similaridades com os humanos quanto aos mecanismos patogênicos da deposição de $A \beta$, o cão tem sido utilizado como modelo animal para as doenças neurodegenerativas associadas à deposição de $A \beta$ sob a forma de placas e nos vasos no neurópilo (YOUSSEF et al., 2016).

A proteína $A \beta$ é originada da clivagem da proteína precursora amiloide, presente na membrana dos neurônios, realizada pelas enzimas $\beta$ e $\gamma$ - secretases (SELKOE, 1994). O acúmulo de $A \beta$ no neurópilo de cães sob a forma de placas senis tem início por volta de nove anos de idade na região do córtex frontal, se estendendo posteriormente para córtex parietal, entorrinal, atingindo por último o córtex occipital, por volta dos 14 anos de idade (BORRÀS et al., 1999; HEAD et al., 2000). Tais placas podem ser classificadas de acordo com sua densidade em difusas ou compactas (PAPAIOANNOU et al., 2001; SCHÜTT et al., 2016). Além disso, as placas também são classificadas de acordo com sua distribuição nas camadas do córtex e densidade (SATOU et al., 1997).

Estudos realizados com cães de diferentes idades demostraram que placas de $A \beta$ presentes nos encéfalos dos animais com aproximadamente 10 anos de idade, classificadas nos estágios Satou I e II, deram lugar à placas mais compactas localizadas nas camadas mais superficiais do córtex, classificadas nos estágios Satou III e IV em animais acima de 15 anos, caracterizando portanto um aumento na severidade da deposição de $A \beta$ com o avançar da idade (SATOU et al., 1997; SCHMIDT et al., 2015; KUMAR et al., 2018). Em contrapartida, outros pesquisadores demonstraram que apesar de haver um aumento de placas compactas relacionado 
ao envelhecimento, esse fenômeno só ocorre até a idade próxima aos 14 anos, onde começa a haver redução das placas compactas e aumento das placas difusas, encontradas dos estágios Satou I e II (PAPAIOANNOU et al., 2001; OZAWA et al., 2016).

A deposição $A \beta$ em vasos do neurópilo e das leptomeninges caracterizam a angiopatia amiloide cerebral (CAA), podendo acometer vasos de diferentes calibres. $O$ acúmulo de $A \beta$ acomete a túnica média dos vasos nos estágios iniciais, avançando posteriormente para as demais camadas com a evolução da doença (ATTEMS, 2005). A deposição da proteína nos vasos pode ser classificada de acordo com sua severidade e camadas acometidas em: leve, moderada e severa, podendo ainda apresentar alterações disóricas, quando o $A \beta$ extravasa da parede do vaso acometido e atinge o neurópilo adjacente (VONSATTEL et al., 1991; ATTEMS, 2005; SCHÜTT et al., 2016). A severidade da CAA em cães, tanto nos vasos do neurópilo quanto nas leptomeninges, aumenta continuamente com o avançar da idade (PAPAIOANNOU et al., 2001; SCHMIDT et al., 2015; SCHÜTT et al., 2016, OZAWA at al, 2016). Diversos estudos realizados em humanos demonstram a ocorrência de CAA em diferentes áreas do encéfalo, com destaque para a lobo occipital, o lobo mais afetado mais severamente entre as regiões encefálicas (ATTEMS, 2005; VINTERS, 2013). Entretanto, pelo conhecimento dos autores, ainda não há estudos detalhados em cães que avaliem a distribuição da CAA no encéfalo.

SCHÜTT et al. (2016) demonstraram correlação significativa entre a severidade da CAA e o estágio de maturação das placas de $A \beta$, porém outros pesquisadores obtiveram resultados divergentes, demonstrando não haver correlação entre a deposição $A \beta$ na parede dos vasos e no neurópilo, evidenciando ainda que tais acúmulos de $A \beta$ ocorrem em sua maioria em áreas não coincidentes do encéfalo (PAPAIOANNOU et al., 2001; OZAWA et al., 2016).

Apesar de diversos estudos terem explorado a relação entre as lesões encontradas no sistema nervoso central (SNC) e sua evolução com a idade, principalmente em relação à deposição de $A \beta$ e sua distribuição no encéfalo dos cães senis, existem algumas lacunas a serem preenchidas, tais como as áreas do encéfalo mais frequentemente acometidas, bem como a evolução do padrão da deposição $A \beta$ e sua relação com a idade. Desta forma, o presente estudo teve como objetivo avaliar a deposição $A \beta$ tanto sob a forma de placas senis no neurópilo como 
nos vasos encefálicos em uma população heterogênea de cães, assim como determinar a distribuição em diferentes áreas do encéfalo e correlacionar a evolução da deposição de $A \beta$ com a idade, raça e porte dos cães.

\subsection{MATERIAIS E MÉTODOS}

\subsubsection{Seleção dos casos}

No presente estudo foram selecionados 32 cães, de raças e idades distintas, provenientes da rotina diagnóstica do Serviço de Patologia do Departamento de Patologia Experimental e Comparada da Faculdade de Medicina Veterinária e Zootecnia (FMVZ) da Universidade de São Paulo (USP) no ano de 2018. Foram coletados os encéfalos de 26 cães senis, com idade entre 8 e 17 anos, além de 6 animais jovens, com idade entre 1 e 7 anos. Para a composição dos grupos experimentais, os cães foram divididos de duas formas distintas. Primeiramente, os mesmos foram divididos em 3 grupos de acordo com o porte: pequeno $(<10 \mathrm{~kg})$; médio (10-25kg); e grande (>25kg). Posteriormente, os cães foram divididos em 3 grupos de acordo com a idade, de 0 a 7 anos, 8 a 12 anos e 13 a 17 anos.

Os animais selecionados foram eutanasiados ou morreram espontaneamente em decorrência de diferentes doenças, nenhuma delas de caráter excludente para o presente estudo, exceto doenças que acometem o SNC. Todos os procedimentos descritos no presente trabalho foram aprovados pela Comissão de Ética no Uso de Animais (CEUA) da Faculdade de Medicina Veterinária e Zootecnia (FMVZ), Universidade de São Paulo (USP) sob o número de protocolo CEUA 5509280119.

\subsubsection{Coleta das amostras}

Os casos selecionados foram necropsiados na rotina do Serviço de Patologia da FMVZ, USP. As amostras de encéfalo foram coletadas e fixadas em solução de formalina tamponada a $10 \%$. Os encéfalos foram então seccionados em corte coronais, onde foram coletados 3 fragmentos, sendo eles: lobo frontal contendo os núcleos da base, lobo temporal com hipocampo e tálamo, e lobo occipital. 


\subsubsection{Avaliação histológica}

As amostras de encéfalo seccionadas e previamente fixadas em formalina tamponada a $10 \%$ foram processadas pelos métodos rotineiros de histologia. As amostras foram desidratadas em concentrações crescentes de álcool etílico, diafanizadas em xilol e incluídas em parafina. Cortes de $5 \mu \mathrm{m}$ foram desparafinados em xilol e reidratados em concentrações decrescentes de álcool etílico. As amostras foram então coradas com hematoxilina e eosina (HE) para avaliação histológica geral do tecido por meio de microscopia óptica. Foi realizada uma análise descritiva das possíveis alterações histológicas encontradas nos encéfalos de cães idosos.

\subsubsection{Imuno-histoquímica}

Cortes de encéfalo com espessura de $5 \mu \mathrm{m}$ em lâminas silanizadas Starfrost $\left(\right.$ Knitte $\left.^{\circledR}\right)$, desparafinados em xilol e reidratados foram submetidos à análise imunohistoquímica (IHQ) para detecção de $A \beta$ e da proteína glial fibrilar ácida (GFAP), utilizando o kit EnVision FLEX System (Dako, Agilent, Santa Clara, California, USA). $\mathrm{Na} I H Q$ para a detecção de $A \beta$, os cortes foram submetidos à três diferentes tipos de recuperação antigênica. Primeiramente foi realizada recuperação enzimática com proteinase K (GE Healthcare ${ }^{\circledR}$ ) $0,05 \%$ durante 10 minutos à $37^{\circ}$, seguida da recuperação por calor com tampão citrato $\mathrm{pH} \mathrm{6,0} \mathrm{em} \mathrm{panela} \mathrm{de} \mathrm{pressão} \mathrm{durante} 15$ minutos. Por último, realizou-se o tratamento com ácido fórmico $85 \%$, durante 10 minutos em temperatura ambiente. Para a detecção de GFAP, a recuperação antigênica foi realizada apenas com a utilização do tampão citrato $\mathrm{pH}$ 6,0 como descrito acima. Em seguida, os cortes foram incubados por 15 minutos em um reagente de bloqueio de peroxidase do kit Envision FLEX. Posteriormente realizouse a incubação com 0 anticorpo primário anti-A $\beta$, monoclonal, produzido em camundongo, clone BAM 01 (6F/3D) (Termo Fisher, Rockford, Illinois, USA), por 14 a 16 horas overnight a $4^{\circ} \mathrm{C}$, na diluição 1:50, e com o anticorpo primário anti-GFAP, policlonal, produzido em coelho (Dako, Agilent, Santa Clara, California, USA) por 1 hora em temperatura ambiente, na diluição 1:8000. Em seguida, o material foi incubado com 0 anticorpo secundário EnVision FLEX/HRP em temperatura ambiente, durante 30 minutos. A reação foi então revelada utilizando o substrato DAB (3,3'-diaminobenzidina) por 14 e 4 minutos para os anticorpos anti-A $\beta$ e anti- 
GFAP, respectivamente, com subsequente contra coloração com hematoxilina por 1 minuto.

Secções de córtex cerebral de um cão com placas de $A \beta$ e angiopatia amiloide cerebral foram utilizadas como controle positivo para o anticorpo anti-A $\beta$. Como controle negativo para $A \beta$ foram utilizados encéfalos de cães jovens. Como controles negativos para a reação foram utilizados soros homólogos não imunes em substituição aos anticorpos primários. Os cortes foram considerados positivos para a detecção da proteína $A \beta$ quando havia intensa marcação no neurópilo sob a forma de placas ou nos vasos intraparenquimatosos e/ou das leptomeninges. Já na imunomarcação de GFAP, a positividade foi confirmada com a visualização da marcação dos astrócitos presentes nas substâncias branca e cinzenta.

\subsubsection{Análise morfométrica de $A \beta$ e GFAP}

A imunomarcação dos fragmentos das lâminas foi analisada sob microscopia óptica e as imagens obtidas foram avaliadas pelo software ImageJ (National Institute of Health, USA).

$\mathrm{Na}$ avaliação da imunomarcação para $A \beta$ na forma de placas, foram selecionados 5 campos, de forma semi-randomizada, não sobrepostos de cada região a ser avaliada (córtex frontal, temporal e occipital), sob a objetiva de 10X (2.535.638,4 $\left.\mu \mathrm{m}^{2} / \mathrm{campo}\right)$ para análise quantitativa. Resumidamente, as imagens captadas, e analisadas por meio do software ImageJ foram inicialmente transformadas em 8 bits, e o threshold foi aplicado em acordo com a imagem original de forma a selecionar as áreas imunomarcadas (Figura 1A e 1B). Em seguida, as áreas referentes à seleção prévia foram mensuradas, estabelecendo $50 \mu \mathrm{m}^{2}$ como área mínima para a análise (Figura 1C). Em cada campo analisado, realizou-se a somatória de todas as áreas de placas detectadas.

Adicionalmente, foi realizada uma análise qualitativa da deposição de $A \beta$ na forma de placas de acordo com a classificação descrita por Satou et al. (1997). Satou et al. (1997) descreve 4 diferentes padrões de deposição de $A \beta$ sob a forma de placas: tipo I: placas com baixa densidade (difusas), de tamanho pequeno, arredondadas e restritas às camadas V e VI do córtex; tipo II: placas difusas, com limites pouco definidos, tendendo a coalescer, se estendendo da camada VI até a III; tipo III: placas densas (compactas), geralmente menores, arredondas, nas camadas 
mais superficiais do córtex, acompanhadas por placas difusas nas camadas mais profundas; e tipo IV: placas densas (placas compactas), arredondadas, distribuídas ao longo de todo o córtex. Uma vez que foram analisadas três diferentes regiões do encéfalo dos cães do presente estudo, quando foi verificada diferença nesta classificação entre as regiões analisadas, a escala mais severa (I até IV) foi utilizada para classificar o caso como um todo.

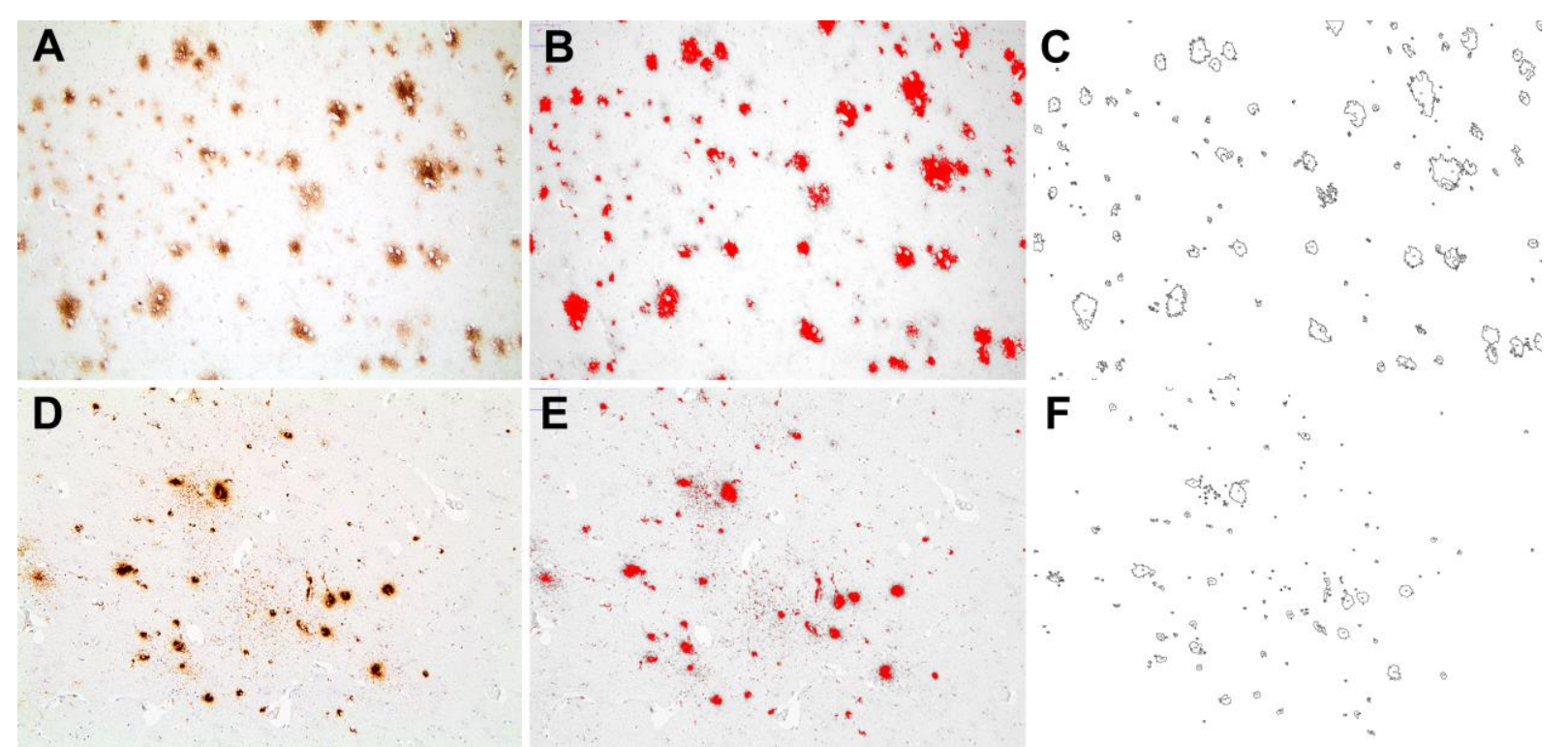

Figura 1 - Método de análise quantitativa das áreas ocupadas pela deposição de $A \beta$ no neurópilo com a utilização do software ImageJ. Deposição de $A \beta$ em forma de placas no córtex frontal do cão da raça Buldogue Francês (caso 23) (A-C) e em vasos do neurópilo no córtex occipital do cão da raça Bull Terrier (caso 21) (D-F). Fotomicrografia original da imunomarcação para $A \beta$ ( $A$ e $D$ ). Estabelecimento do threshold na imagem de 8 bits ( $\mathrm{B}$ e E). Quantificação das áreas imunomarcadas (C e F). Objetivas: 10X (A-C); 20X (D-F). Fonte: (RODRIGUES, L.L, 2019).

$\mathrm{Na}$ análise da deposição de $\mathrm{A} \beta$ nos vasos do neurópilo, foram selecionados também 5 campos, de forma semi-randomizada, não sobrepostos de cada corte do encéfalo (córtex frontal, temporal e occipital) sob a objetiva de 20X (621.661,4 $\mu \mathrm{m}^{2}$ /campo) para avaliação quantitativa dos mesmos, semelhante ao procedimento descrito para a análise das placas (Figura 1D-F). Além disso, tanto os vasos do neurópilo como leptomeníngeos foram avaliados qualitativamente por meio do escore estabelecido por Vonsattel et al. (1991), variando de deposição de $A \beta$ discreta a severa, podendo ainda apresentar extravasamento do $A \beta$ para o neurópilo adjacente, caracterizando as alterações disóricas. 
A avaliação da imunomarcação para a GFAP foi realizada por meio de método semi-quantitativo, avaliando-se 5 campos sob a objetiva 40X selecionados de forma semi-randomizada, não sobrepostos da seguinte maneira: média de 0 a 2 astrócitos/campo (-); média de até 10 astrócitos/campo (+); média dede 10 a 20 astrócitos/campo (++); e média superior a 20 astrócitos/campo .

\subsubsection{Análise estatística}

Foi realizada análise estatística descritiva de todos os dados obtidos, além de testes estatísticos específicos de acordo com a distribuição (paramétrica ou não paramétrica) apresentada pelos dados. $O$ teste de Shapiro-Wilk foi utilizado para testar a distribuição das amostras. Para avaliação da deposição de $A \beta$, classificada de acordo com Satou et al. (1997); além da deposição de $A \beta$ nos vasos (CAA); e imunomarcação de astrócitos (GFAP), relacionando-os com a idade dos animais, foi utilizado o coeficiente de correlação de Spearman. $O$ teste exato de Fisher foi utilizado para avaliar a associação entre a imunomarcação por GFAP e a idade dos animais, além da relação entre CAA e deposição de $A \beta$ sob a forma de placas senis. Além disso, o teste exato de Fisher foi utilizado para avaliar a relação entre CAA e a presença de micro-hemorragias no neurópilo. $\mathrm{Na}$ avaliação entre as áreas do encéfalo acometidas pela deposição de $A \beta$ foram utilizados os testes de Friedman $e$ Tukey. O teste de Kruskal Wallis foi utilizado para avaliar a relação entre a astrocitose (GFAP) e a deposição de $A \beta$ sob a forma de placas senis. Para a avaliação entre os grupos por porte e idade, e a deposição de $A \beta$, foram utilizados a análise de variância com 2 fatores e o teste de Mann-Whitney. $O$ teste de Levene foi utilizado para testar a homocedasticidade das amostras. O nível de significância a ser utilizado foi de $p<0,05$. Os dados obtidos foram analisados por meio do programa estatístico SPSS 20.0 (IBM).

\subsection{RESULTADOS}

\subsubsection{Cães}

As características dos cães selecionados para o presente estudo, tais como raça, idade e porte estão apresentados no Quadro 1. Os animais de grande porte 
apresentaram maior representatividade na totalidade dos casos avaliados $(43 \%)$, seguidos pelos de porte pequeno (31\%). Quanto ao sexo, $62,5 \%$ dos animais eram fêmeas e $37,5 \%$ machos. No estudo, foram avaliados animais de diversas raças, sendo os animais sem raça definida os que apresentaram maior representatividade (18\%), seguido da raça Poodle (12\%) e American Pitbull Terrier (12\%). Os animais foram ainda divididos em grupos de acordo com idade, sendo 6 animais (18\%) com idade entre 1 e 7 anos, 16 animais (50\%) entre 8 e 12 anos e 10 animais (38\%) entre 13 e 17 anos.

Quadro 1 - Raça, idade, sexo e porte dos cães avaliados

\begin{tabular}{|c|c|c|c|c|}
\hline Caso no. & Raça & $\begin{array}{c}\text { Idade } \\
\text { (anos) }\end{array}$ & Sexo & Porte \\
\hline 1 & Dobermann & 1 & $\mathrm{~F}$ & $\mathrm{G}$ \\
\hline 2 & Spitz Alemão & 2 & $\mathrm{~F}$ & $\mathrm{P}$ \\
\hline 3 & Shih Tzu & 5 & $\mathrm{M}$ & $\mathrm{P}$ \\
\hline 4 & Spitz Alemão & 5 & $\mathrm{~F}$ & $\mathrm{P}$ \\
\hline 5 & Golden Retriever & 6 & $\mathrm{~F}$ & $\mathrm{G}$ \\
\hline 6 & Dogue de Bordeaux & 6 & $\mathrm{~F}$ & $\mathrm{G}$ \\
\hline 7 & Pastor Alemão & 8 & $\mathrm{M}$ & $\mathrm{G}$ \\
\hline 8 & Pastor Belga Malinois & 8 & $\mathrm{M}$ & $\mathrm{G}$ \\
\hline 9 & Golden Retriever & 8 & $\mathrm{M}$ & $\mathrm{G}$ \\
\hline 10 & Dachshund & 9 & $\mathrm{M}$ & $\mathrm{P}$ \\
\hline 11 & SRD & 9 & $\mathrm{M}$ & $\mathrm{G}$ \\
\hline 12 & Golden Retriever & 9 & $\mathrm{M}$ & $\mathrm{G}$ \\
\hline 13 & SRD & 10 & $\mathrm{~F}$ & $\mathrm{M}$ \\
\hline 14 & American Pit Bull Terrier & 10 & $\mathrm{~F}$ & $\mathrm{G}$ \\
\hline 15 & SRD & 10 & $\mathrm{~F}$ & $\mathrm{M}$ \\
\hline 16 & Poodle & 10 & $\mathrm{~F}$ & $\mathrm{P}$ \\
\hline 17 & SRD & 10 & $\mathrm{~F}$ & $\mathrm{M}$ \\
\hline 18 & Dachshund & 10 & $\mathrm{~F}$ & $\mathrm{P}$ \\
\hline 19 & Rottweiler & 11 & $\mathrm{~F}$ & $\mathrm{G}$ \\
\hline 20 & SRD & 11 & $\mathrm{~F}$ & $\mathrm{M}$ \\
\hline 21 & Bull Terrier & 12 & $\mathrm{M}$ & $\mathrm{M}$ \\
\hline
\end{tabular}




\begin{tabular}{|c|c|c|c|c|}
\hline Caso no. & Raça & $\begin{array}{c}\text { Idade } \\
\text { (anos) }\end{array}$ & Sexo & Porte \\
\hline 22 & Boxer & 12 & $\mathrm{M}$ & $\mathrm{G}$ \\
\hline 23 & Buldogue Francês & 13 & $\mathrm{M}$ & $\mathrm{M}$ \\
\hline 24 & American Pit Bull Terrier & 13 & $\mathrm{M}$ & $\mathrm{G}$ \\
\hline 25 & American Pit Bull Terrier & 13 & $\mathrm{M}$ & $\mathrm{G}$ \\
\hline 26 & Maltês & 13 & $\mathrm{~F}$ & $\mathrm{P}$ \\
\hline 27 & Poodle & 14 & $\mathrm{~F}$ & $\mathrm{P}$ \\
\hline 28 & Cocker Spaniel & 14 & $\mathrm{~F}$ & $\mathrm{M}$ \\
\hline 29 & SRD & 14 & $\mathrm{~F}$ & $\mathrm{M}$ \\
\hline 30 & American Pit Bull Terrier & 15 & $\mathrm{~F}$ & $\mathrm{G}$ \\
\hline 31 & Poodle & 17 & $\mathrm{~F}$ & $\mathrm{P}$ \\
\hline 32 & Poodle & 17 & $\mathrm{~F}$ & $\mathrm{P}$ \\
\hline
\end{tabular}

Sexo: M - macho; F - fêmea. Porte: P - pequeno; M - médio; G - grande. Fonte: (RODRIGUES, L.L, 2019).

\subsubsection{Análises macroscópica e histológica}

À avaliação macroscópica, os encéfalos dos animais senis (acima de oito anos de idade) apresentaram diversas alterações, entre elas atrofia do encéfalo com redução dos giros e alargamento dos sulcos, além de dilatação dos ventrículos (Figura 2).

$\mathrm{Na}$ avaliação histológica, perda e degeneração neuronais de variáveis graus de intensidade foram visualizadas em todos os animais acima de oito anos, sendo mais severas nos animais com idade mais avançada. Diversas áreas do córtex cerebral, tais como o córtex frontal, temporal e occipital, além do hipocampo (Figura 3A). Além disso, áreas com neuroniofagia foram identificadas em diferentes regiões do córtex, evidenciando a fagocitose dos neurônios degenerados pela micróglia (Figura 3B). 


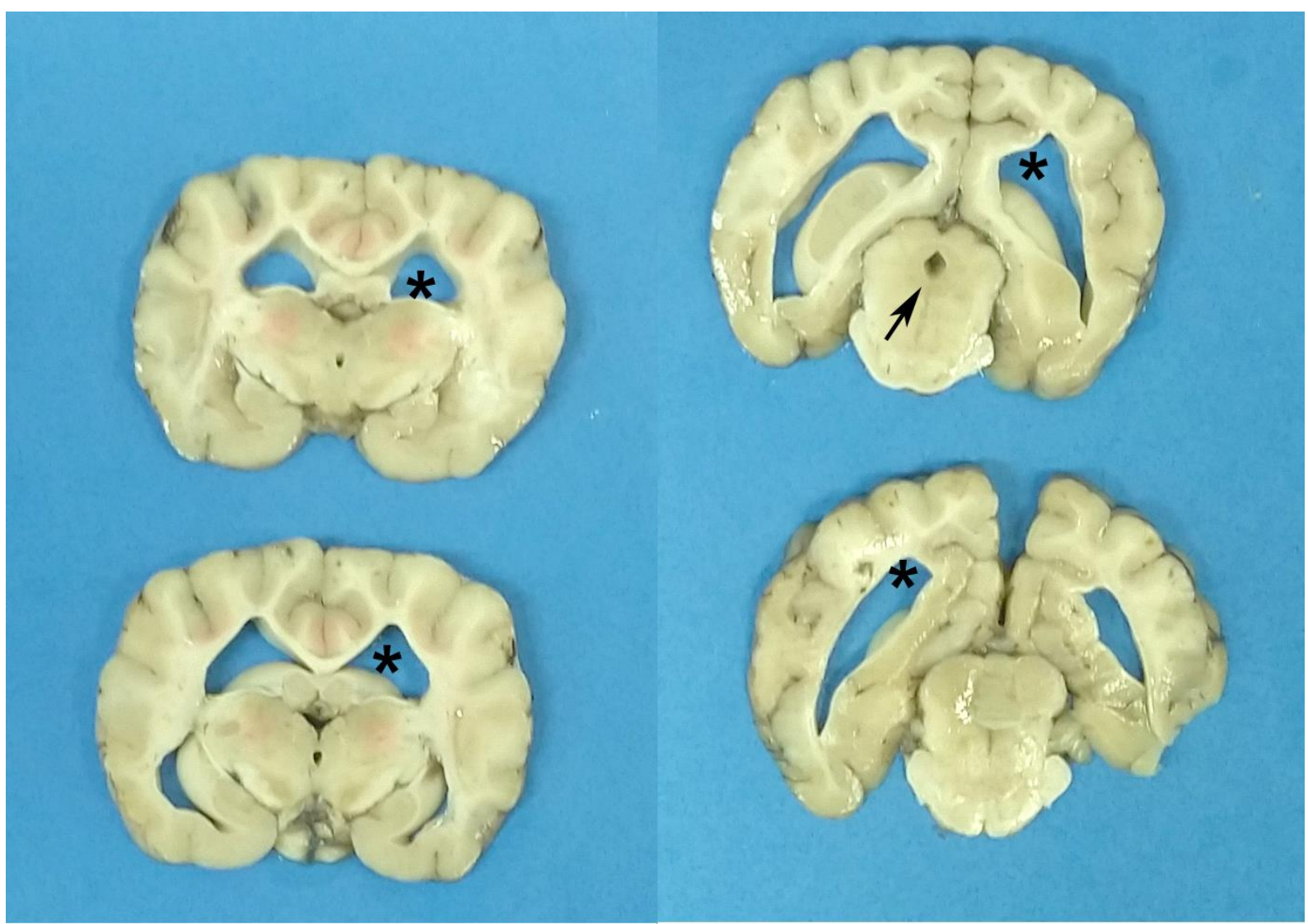

Figura 2 - Encéfalo de um cão de 17 anos, da raça Poodle (caso 31), apresentando dilatação dos ventrículos laterais (asteriscos) e do aqueduto mesencefálico (seta). Fonte: (RODRIGUES, L.L, 2019).

Os casos nos quais foram detectadas perda e degeneração neuronais, comumente eram acompanhados por áreas de gliose difusas no neurópilo e substância branca, por vezes formando acúmulos focais, chamados nódulos gliais. Acúmulos de pigmentos intracelulares foram visualizados em diversas áreas do encéfalo, entre eles a lipofuscina, que se encontrava presente em $92 \%$ dos animais acima de oito anos (Figura $3 \mathrm{C}$ ). Outro pigmento observado foi a neuromelanina, presente em 3 animais dos grupos acima de oito anos, representando $11,5 \%$ da totalidade dos casos destes grupos (Figura 3D). Também foram observados espessamento e calcificação das meninges, sendo esta última visualizada em 5 animais $(19,2 \%)$ com idade superior a oito anos. Outro achado detectado nos encéfalos de cães senis avaliados foi a vacuolização difusa da substância branca de graus variados de intensidade. 

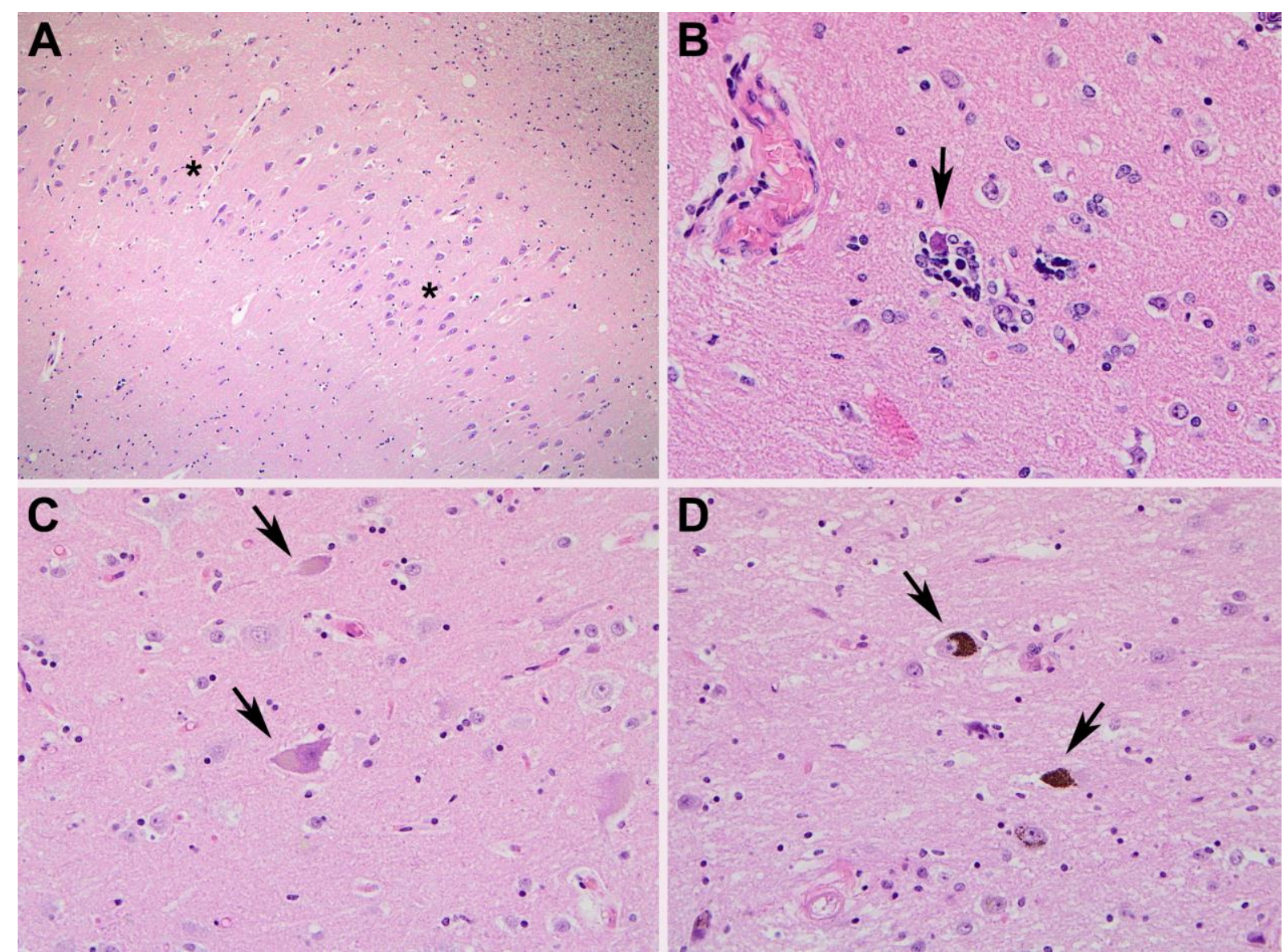

Figura 3 - Lesões histológicas no sistema nervoso central de cães senis. (A) Área do giro denteado (hipocampo) evidenciando redução no número de neurônios (asteriscos), em um cão da raça Pitbull de 15 anos de idade (caso 30). (B) Micróglia em processo de fagocitose de neurônio degenerado no córtex frontal em um cão da raça Buldogue Francês de 13 anos de idade (caso 23), caracterizando neuroniofagia (seta). (C) Inclusão citoplasmática de lipofuscina em neurônio no córtex frontal (setas) de cão da raça Pitbull de 13 anos de idade (caso 24). (D) Inclusão citoplasmática de neuromelanina em neurônio do córtex temporal (setas), em cão da raça Pitbull de 13 anos de idade (caso 24). Coloração de hematoxilina e eosina. Objetivas: (A) 10X. (B-D) 40X. Fonte: (RODRIGUES, L.L, 2019).

O espessamento dos vasos do neurópilo e leptomeníngeos foi um achado bastante frequente, se apresentando sob duas formas: a primeira, caracterizada por espessamento de parede vascular de característica eosinofílica e acelular, acometendo inicialmente a túnica média nos casos mais brandos e se estendendo para as demais camadas com a evolução do quadro, condição também conhecida como hialinização vascular (Figura 4A). No outro tipo de espessamento havia um aumento na espessura da túnica médica, porém com celularidade (Figura 4B). Dos casos avaliados, 14 animais com mais de oito anos (53\%) apresentavam hialinização vascular, e 21 animais (80\%) apresentavam o espessamento celular da túnica média. Outro achado importante foi a presença de micro-hemorragias 
perivasculares distribuídas por diversas áreas do córtex cerebral, visualizadas em $42 \%$ dos animais senis avaliados (Figuras 4C e 4D).

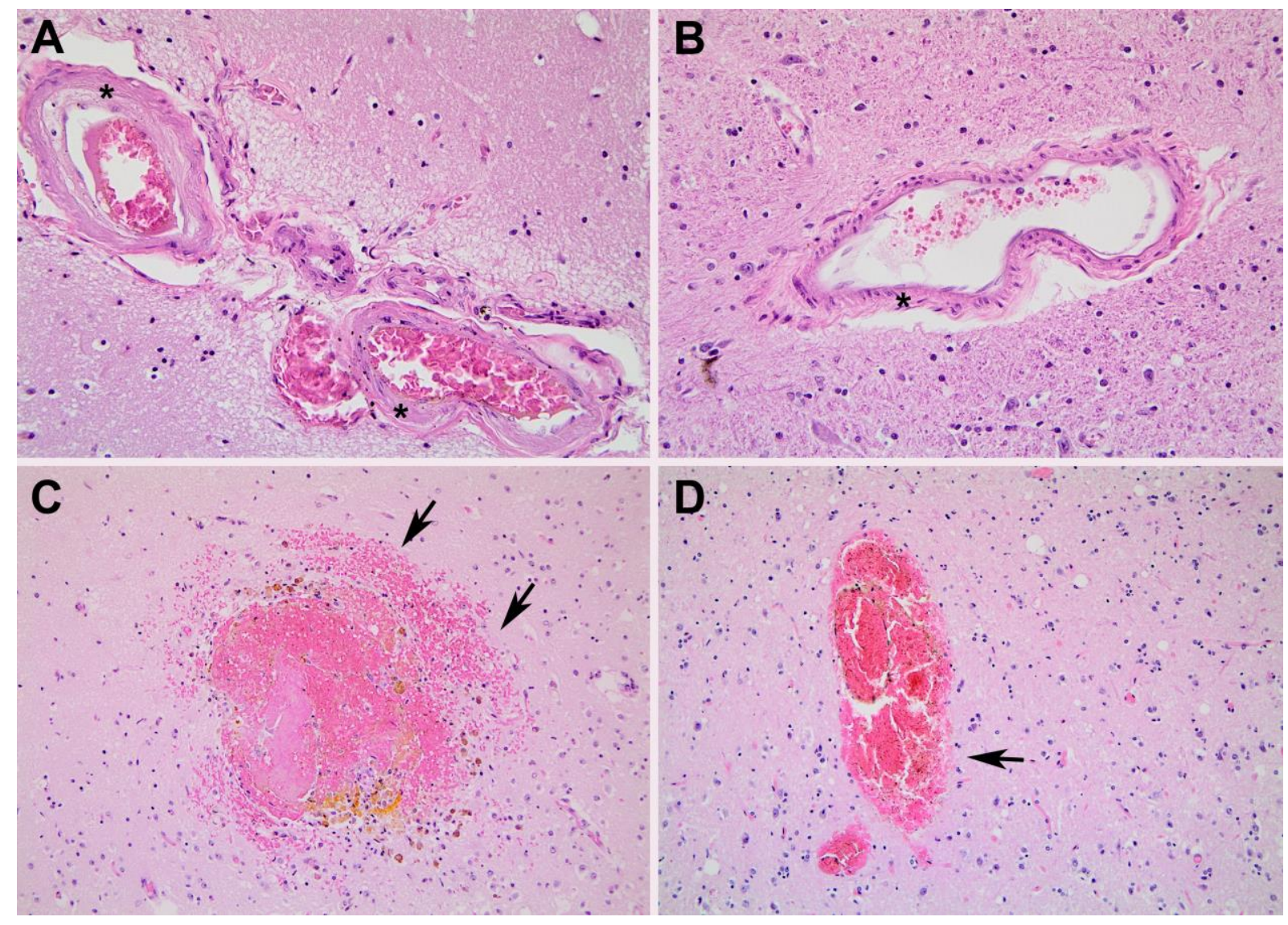

Figura 4 - Lesões no sistema nervoso central de cães senis: espessamento de vasos e hemorragias. (A) Artérias da leptomeninge apresentando espessamento eosinofílico e acelular da túnica média da parede vascular (asteriscos), em cão de da raça Pit Bull de 13 anos (caso 24). (B) Espessamento com celularidade da túnica média de uma pequena artéria no neurópilo (asterisco) de um cão da raça Poodle com 10 anos de idade (caso 16). (C) Micro-hemorragia perivascular com hemossiderose no córtex frontal (setas) em um cão da raça Poodle de 17 anos (caso 31). (D) Micro-hemorragia perivascular em córtex temporal (seta) em um cão Poodle de 17 anos (caso 31). Coloração de hematoxilina e eosina. Objetivas: (A, C, D) 20x. (B) 40x. Fonte: (RODRIGUES, L.L, 2019).

\subsubsection{Análise imuno-histoquímica}

À IHQ com o anticorpo anti- $A \beta, 22$ casos apresentaram imunomarcação, a partir dos oito anos de idade, em pelo menos uma das regiões do encéfalo estudadas, representando $85 \%$ (22/26) da totalidade dos casos acima de oito anos (Quadro 2). Tal marcação se apresentou sob duas formas: a primeira, com a deposição extracelular do peptídeo $A \beta$ no neurópilo do córtex cerebral formando 
placas de distribuição irregular ou no formato de fita, denominado "ribbon-like" no hipocampo; e a segunda com deposição de $A \beta$ na parede dos vasos do neurópilo e leptomeníngeos irregularmente distribuída, caracterizando a CAA (Quadro 2). Os animais com idade entre 1 e 7 anos não apresentaram imunomarcação para $A \beta$.

As placas formadas pela deposição de $A \beta$ no neurópilo foram classificadas de acordo com sua densidade em difusas ou compactas. As placas difusas possuíam menor densidade e com maior área de deposição de $A \beta$ por placa (Figura 5A). Já as placas compactas eram mais densas, e de menor tamanho quando comparado às placas difusas (Figura 5B). Tanto as placas compactas quanto difusas apresentavam-se por diversas vezes circundando grupos de neurônios. Foi observada a presença de $A \beta$ sob a forma de placas em pelo menos uma das regiões analisadas (córtex frontal, temporal e/ou occipital) em 19 dos 26 cães senis (73\%), e representando $86 \%$ dos casos em que houve imunomarcação para $A \beta(19 / 22)$.

As áreas totais ocupadas pelo $A \beta$ no neurópilo, bem como nas regiões específicas do SNC estão apresentadas na Figura 6. A proteína $A \beta$ na forma de placas no córtex dos animais do presente estudo foram detectadas a partir de nove anos de idade. Foi observada correlação positiva entre a área total ocupada pelas placas de $A \beta$ no neurópilo, resultado da somatória das áreas nas três regiões do cérebro avaliadas, e a idade dos animais, evidenciando aumento na área de deposição de $A \beta$ com o aumento da idade dos animais $\left(p<0,05 ; r^{2}=0,12\right)$. Entretanto, quando se avaliou a quantidade de $A \beta$ depositada sob a forma de placas e a idade de cães senis acima de oito anos, não houve correlação entre aumento da idade e deposição de $A \beta$ no encéfalo $(p>0,05)$. Semelhantemente, quando avaliamos a área em placas de $A \beta$ nos animais divididos em grupos de acordo com a idade e porte, não foi identificada correlação entre a área de $A \beta$ e a idade dos animais, nos diferentes grupos por porte $(p>0,05)$. 
Quadro 2 - Imunomarcação para beta-amiloide $(A \beta)$ no encéfalo de cães

\begin{tabular}{|c|c|c|c|c|c|c|}
\hline Caso no. & $\begin{array}{l}\text { Idade } \\
\text { (anos) }\end{array}$ & $\begin{array}{l}\mathrm{IHQ} \\
\mathrm{A} \beta\end{array}$ & $\begin{array}{c}\mathrm{A} \beta \text { - } \\
\text { Placas } \\
\text { (Satou) }\end{array}$ & $\begin{array}{c}\text { A } \beta \\
\text { Hipocampo }\end{array}$ & $\begin{array}{c}A \beta- \\
\text { vasos } \\
\text { (CAA) }\end{array}$ & $\begin{array}{c}A \beta \\
\text { Placa+Vasos }\end{array}$ \\
\hline 1 & 1 & $\mathrm{~N}$ & $\mathrm{~N}$ & $\mathrm{~N}$ & $\mathrm{~N}$ & $\mathrm{~N}$ \\
\hline 2 & 2 & $\mathrm{~N}$ & $\mathrm{~N}$ & $\mathrm{~N}$ & $\mathrm{~N}$ & $\mathrm{~N}$ \\
\hline 3 & 5 & $\mathrm{~N}$ & $\mathrm{~N}$ & $\mathrm{~N}$ & $\mathrm{~N}$ & $\mathrm{~N}$ \\
\hline 4 & 5 & $\mathrm{~N}$ & $\mathrm{~N}$ & $\mathrm{~N}$ & $\mathrm{~N}$ & $\mathrm{~N}$ \\
\hline 5 & 6 & $\mathrm{~N}$ & $\mathrm{~N}$ & $\mathrm{~N}$ & $\mathrm{~N}$ & $\mathrm{~N}$ \\
\hline 6 & 6 & $\mathrm{~N}$ & $\mathrm{~N}$ & $\mathrm{~N}$ & $\mathrm{~N}$ & $\mathrm{~N}$ \\
\hline 7 & 8 & $\mathrm{~N}$ & $\mathrm{~N}$ & $\mathrm{~N}$ & $\mathrm{~N}$ & $\mathrm{~N}$ \\
\hline 8 & 8 & $\mathrm{~N}$ & $\mathrm{~N}$ & $\mathrm{~N}$ & $\mathrm{~N}$ & $\mathrm{~N}$ \\
\hline 9 & 8 & $S$ & $\mathrm{~N}$ & $S$ & $\mathrm{~N}$ & $\mathrm{~N}$ \\
\hline 10 & 9 & $S$ & II & $\mathrm{N}$ & $S$ & $S$ \\
\hline 11 & 9 & $S$ & II & $\mathrm{N}$ & $S$ & $S$ \\
\hline 12 & 9 & $S$ & IV & $S$ & $\mathrm{~N}$ & $\mathrm{~N}$ \\
\hline 13 & 10 & $S$ & I & $\mathrm{N}$ & $\mathrm{S}^{*}$ & $S$ \\
\hline 14 & 10 & $\mathrm{~N}$ & $\mathrm{~N}$ & $\mathrm{~N}$ & $\mathrm{~N}$ & $\mathrm{~N}$ \\
\hline 15 & 10 & $S$ & II & $\mathrm{N}$ & $S$ & $S$ \\
\hline 16 & 10 & $S$ & $\mathrm{~N}$ & $\mathrm{~N}$ & $\mathrm{~N}$ & $\mathrm{~N}$ \\
\hline 17 & 10 & $S$ & IV & $S$ & $S$ & $S$ \\
\hline 18 & 10 & $S$ & II & $\mathrm{N}$ & $S$ & $S$ \\
\hline 19 & 11 & $S$ & $\mathrm{I}$ & $S$ & $S$ & $S$ \\
\hline 20 & 11 & $\mathrm{~N}$ & $\mathrm{~N}$ & $\mathrm{~N}$ & $\mathrm{~N}$ & $\mathrm{~N}$ \\
\hline 21 & 12 & $S$ & III & $S$ & $S$ & $S$ \\
\hline 22 & 12 & $S$ & III & $S$ & $S$ & $S$ \\
\hline 23 & 13 & $S$ & IV & $\mathrm{N}$ & $\mathrm{S}^{*}$ & $\mathrm{~N}$ \\
\hline 24 & 13 & $S$ & III & $\mathrm{N}$ & $S$ & $S$ \\
\hline 25 & 13 & $S$ & III & $S$ & $S^{*}$ & $\mathrm{~N}$ \\
\hline 26 & 13 & $S$ & I & $\mathrm{N}$ & $S$ & $S$ \\
\hline 27 & 14 & $S$ & II & $S$ & $S$ & $S$ \\
\hline 28 & 14 & $S$ & II & $\mathrm{N}$ & $S$ & S \\
\hline 29 & 14 & $\mathrm{~S}$ & III & $\mathrm{N}$ & $\mathrm{S}$ & $S$ \\
\hline
\end{tabular}




\begin{tabular}{|c|c|c|c|c|c|c|}
\hline Caso no. & $\begin{array}{l}\text { Idade } \\
\text { (anos) }\end{array}$ & $\begin{array}{l}\mathrm{IHQ} \\
\mathrm{A} \beta\end{array}$ & $\begin{array}{c}A \beta- \\
\text { Placas } \\
\text { (Satou) }\end{array}$ & $\begin{array}{c}A \beta \\
\text { Hipocampo }\end{array}$ & $\begin{array}{c}A \beta- \\
\text { vasos } \\
\text { (CAA) }\end{array}$ & $\begin{array}{c}A \beta \\
\text { Placa+Vasos }\end{array}$ \\
\hline 30 & 15 & $S$ & I & $S$ & $S$ & $S$ \\
\hline 31 & 17 & $S$ & $\mathrm{~N}$ & $\mathrm{~N}$ & $S$ & $\mathrm{~N}$ \\
\hline 32 & 17 & $S$ & III & $S$ & $S$ & $S$ \\
\hline $\begin{array}{c}\text { Total cães } \\
\text { A } \beta+\end{array}$ & - & 22 & 19 & 9 & 19 & 16 \\
\hline$\%$ Total & $\begin{array}{l}100 \% \\
(32 / 32)\end{array}$ & $\begin{array}{c}69 \% \\
(22 / 32)\end{array}$ & $\begin{array}{c}59 \% \\
(19 / 32)\end{array}$ & $28 \%(9 / 32)$ & $\begin{array}{c}60 \% \\
(19 / 32)\end{array}$ & $50 \%(16 / 32)$ \\
\hline $\begin{array}{c}\text { \% Cães } \\
\text { senis } \\
\text { (acima de } \\
8 \text { anos de } \\
\text { idade) }\end{array}$ & $\begin{array}{c}81 \% \\
(26 / 32)\end{array}$ & $\begin{array}{c}85 \% \\
(22 / 26)\end{array}$ & $\begin{array}{c}73 \% \\
(19 / 26)\end{array}$ & $35 \%(9 / 26)$ & $\begin{array}{c}73 \% \\
(19 / 26)\end{array}$ & $61 \%(16 / 26)$ \\
\hline
\end{tabular}

$A \beta$ : beta-amiloide. S: sim, havia imunomarcação para $A \beta$. N: não, não havia imunomarcação para $A \beta$. $I H Q$ - $A \beta$ : imunomarcação para $A \beta$ independente da área. $A \beta$ - Placas (Satou): $A \beta$ depositada na forma de placas no córtex cerebral e classificado de acordo com Satou et al. (1997), sendo que todas com classificação de I, II, III ou IV, tiveram imunomarcação para $A \beta$. $A \beta$ - Hipocampo: $A \beta$ depositada na forma "ribbon like" no hipocampo. $A \beta$ - vasos (CAA): $A \beta$ depositada na parede de vasos leptomeníngeos e/ou do neurópilo, caracterizando a CAA (angiopatia amiloide cerebral). A $\beta$ Placa+Vasos: $A \beta$ depositado tanto na forma de placas e concomitantemente em vasos leptomeníngeos e/ou do neurópilo. Total cães $A \beta+$ : total de cães imunomarcados para $A \beta$, na forma de placas, no hipocampo, em vasos, e placas concomitantemente com vasos leptomeníngeos e/ou do neurópilo. * somente imunomarcação para $A \beta$ nos vasos leptomeníngeos. Fonte: (RODRIGUES, L.L, 2019). 


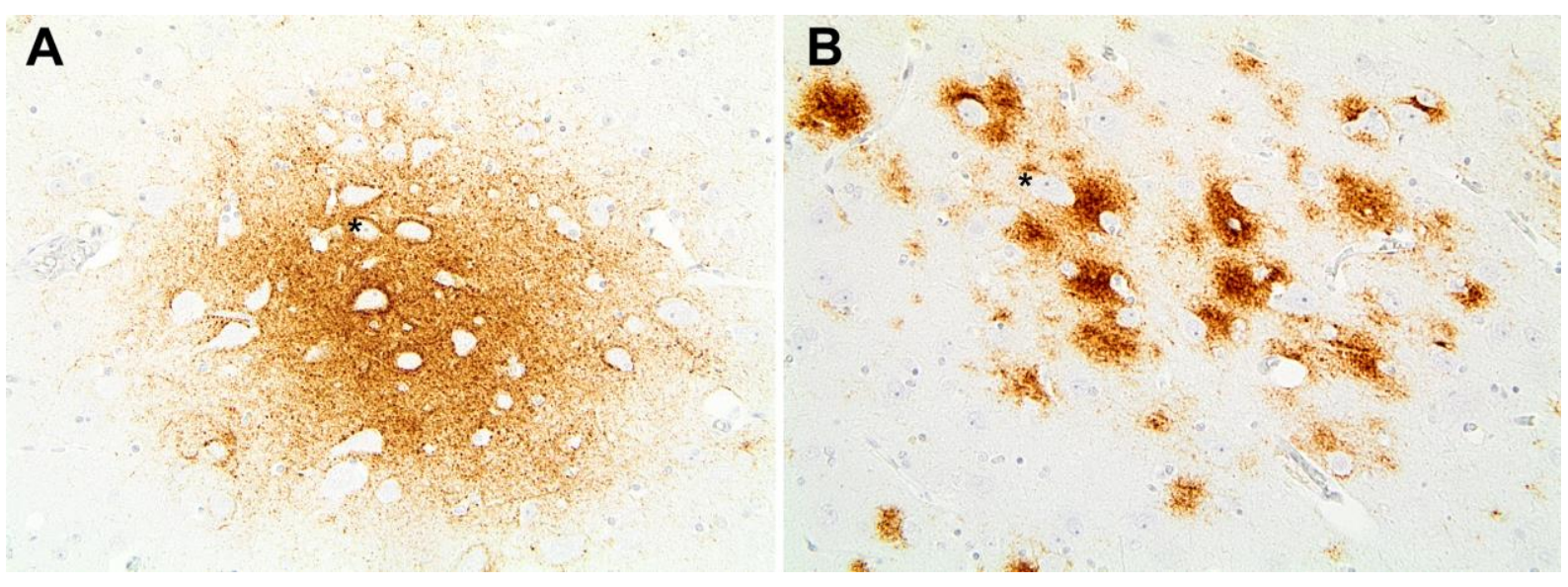

Figura 5 - Lesões no sistema nervoso central de cães senis, detecção da deposição de $A \beta$ no neurópilo. (A) Placa difusa circundando grupo de neurônios (asterisco) no córtex frontal de um cão de 13 anos de idade da raça Pit Bull (caso 25). (B) Placas compactas ao redor de neurônios (asterisco) no córtex frontal de um cão de 17 anos de idade da raça Poodle (caso 32). Objetiva: 40X. Fonte: (RODRIGUES, L.L, 2019).

Quanto a distribuição das placas de $A \beta$ nos córtices frontal, temporal e occipital, não houve diferença estatística significativa $(p>0,05)$ em relação a quantidade de deposição de $A \beta$ na forma de placas entre essas diferentes regiões analisadas.

As placas foram classificadas, na escala de Satou et al. (1997), de acordo com a camada do córtex acometida em conjunto com densidade das placas (difusa ou compacta) (Figura 7). Utilizando a classificação estabelecida por tal autor, podemos distribuir os casos do presente estudo da seguinte maneira: Satou I: $21 \%$ (4/19); Satou II: 31,5\% (6/19); Satou III: 31,5\% (6/19); e Satou IV: 16\% (3/19) (Quadro 2). Não foi observada correlação entre os padrões de deposição de $A \beta$ enquadrados na escala Satou et al. (1997) e a idade dos animais avaliados no presente trabalho $(p>0,05)$. Quando os cães foram divididos em grupos de acordo com o porte com intuito de normalizar as idades, também não houve correlação entre a idade e a classificação proposta por Satou et al. (1997) ( $p>0,05)$. 
Frontal cortex

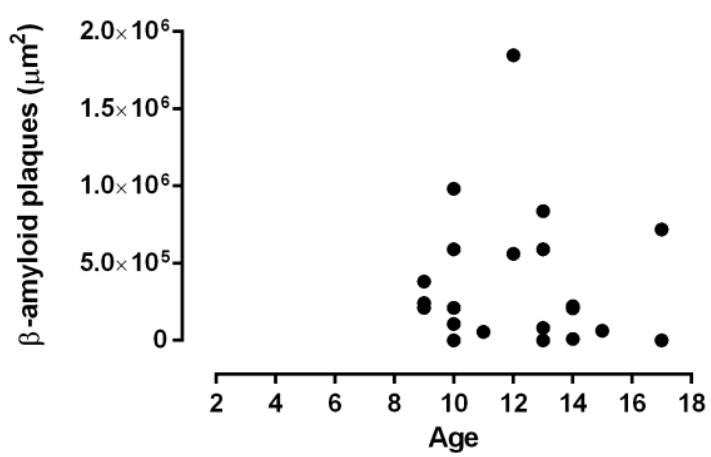

Occipital cortex

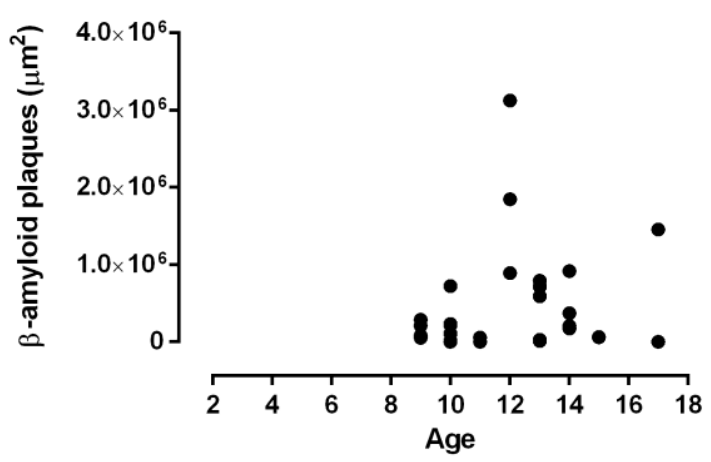

Temporal cortex

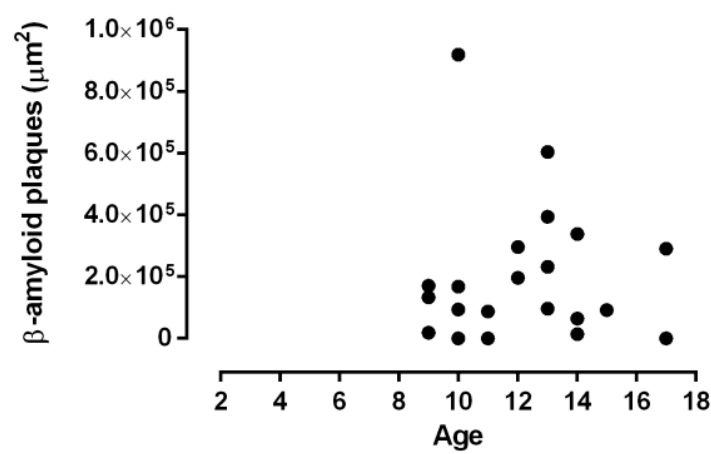

Total $\beta$-amyloid load

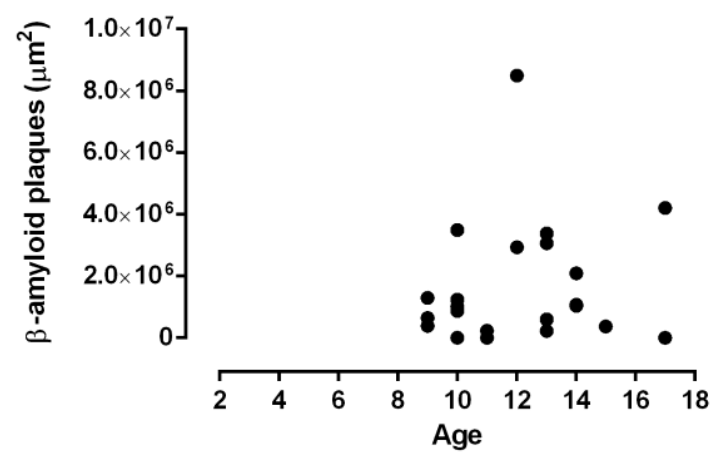

Figura 6 - Quantidade de deposição de $A \beta$ sob a forma de placas mensurada nas diferentes áreas do encéfalo de cães (córtices frontal, temporal, occipital e a totalidade de $A \beta$ nas três diferentes áreas). Houve correlação positiva entre a área total ocupada pelas placas de $A \beta$ no neurópilo, e a idade dos animais, evidenciando aumento na área de deposição de $A \beta$ com o aumento da idade dos animais $\left(p<0,05 ; r^{2}=0,12\right)$. Entretanto, não houve diferença estatisticamente significativa em relação a quantidade de $A \beta$ nas três diferentes áreas analisadas ( $p>0,05)$. Fonte: (RODRIGUES, L.L, 2019).

Nas secções do hipocampo, a deposição de $A \beta$ com padrão semelhante a uma fita ("ribbon-like"), presente na camada externa do giro denteado, foi detectada em 9 casos, representado $35 \%$ dos cães senis (9/26), e correspondendo a $41 \%$ (9/22) dos casos com algum tipo de imunomarcação para Aß (Figura 8) (Quadro 2). 


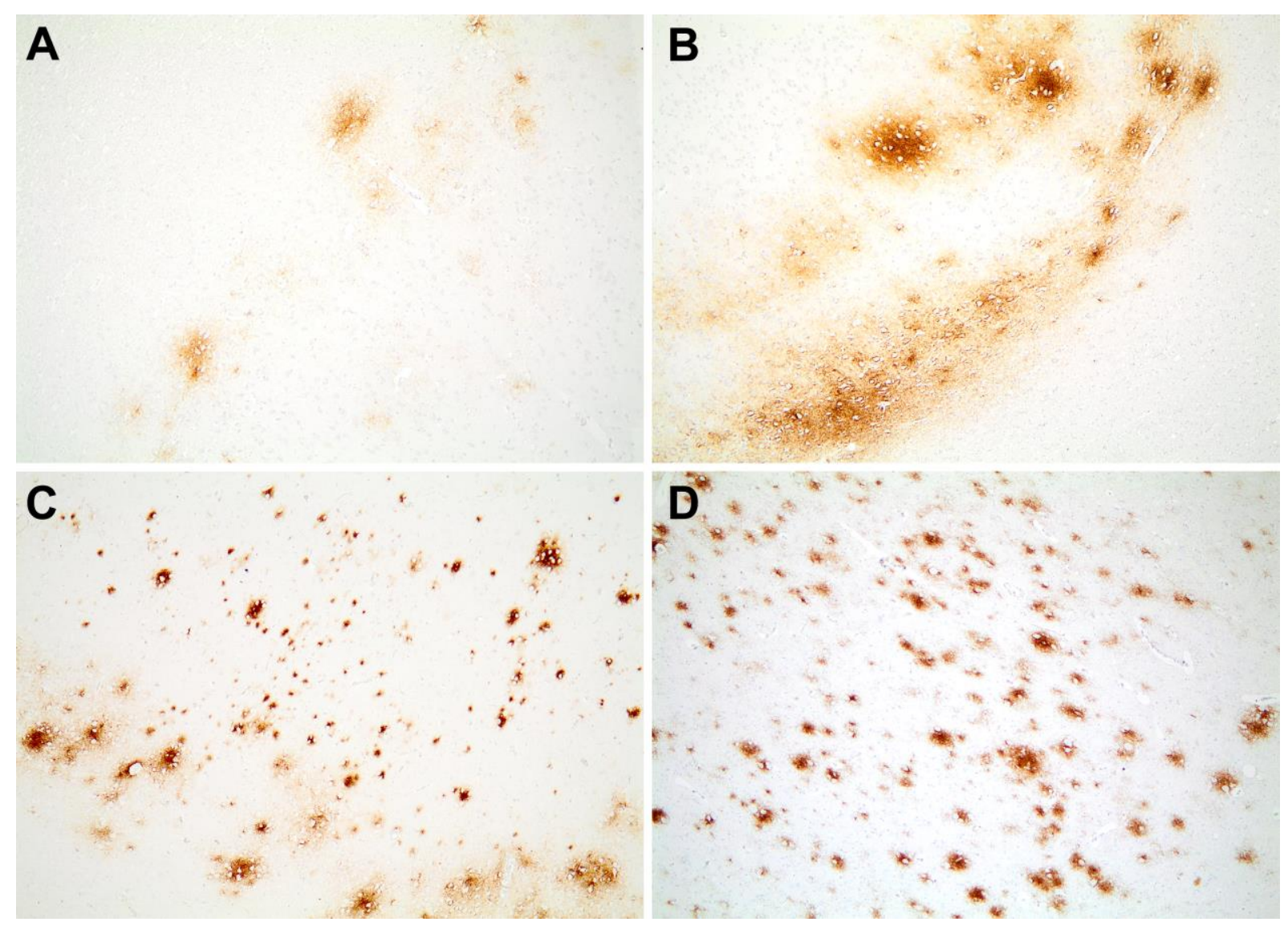

Figura 7 - Lesões no sistema nervoso central de cães senis, detecção da deposição de $A \beta$ no neurópilo - classificação segundo Satou et al. (1997). (A) Tipo I: placas com baixa densidade (difusas), de tamanho pequeno, arredondadas e restritas às camadas $\mathrm{V}$ e VI do córtex. Cão raça Boxer de 12 anos de idade (caso 22). (B) Tipo II: placas difusas, com limites pouco definidos, tendendo a coalescer, se estendendo da camada VI até a III do córtex. Cão sem raça definida de 10 anos de idade (caso 17). (C) Tipo III: placas densas (compactas), arredondadas, nas camadas mais superficiais do córtex, acompanhadas por placas difusas nas camadas mais profundas (porção inferior da imagem). Cão da raça Poodle de 17 anos de idade (caso 32). (D) Tipo IV: placas densas (compactas), arredondadas, distribuídas ao longo de todo o córtex. Cão da raça Buldogue Francês de 13 anos de idade (caso 23). Objetiva: 10X. Fonte: (RODRIGUES, L.L, 2019). 


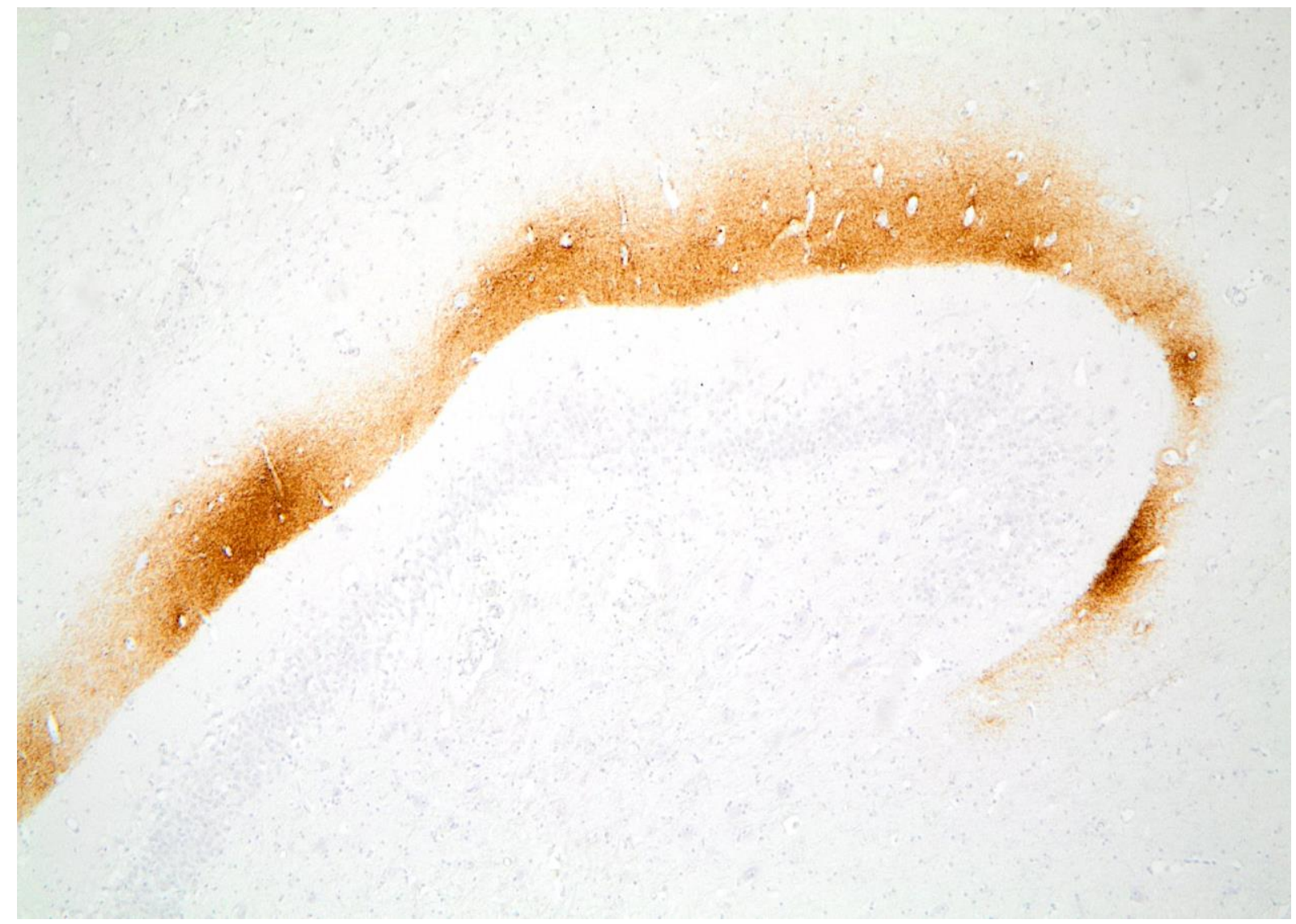

Figura 8 - Lesões no sistema nervoso central de cães senis detecção da deposição de $A \beta$ no neurópilo. Imunomarcação de $A \beta$ com padrão semelhante a uma fita ("ribbon-like") no giro denteado do hipocampo de um cão de 13 anos da raça Pit Bull (caso 25). Objetiva: 10x. Fonte: (RODRIGUES, L.L, 2019).

A proteína $A \beta$ também foi detectada em vasos de diferentes calibres, principalmente em artérias, arteríolas e capilares localizados tanto no neurópilo da substância cinzenta como nas leptomeninges, caracterizando a CAA. Dos cães senis, acima de oito anos de idade, avaliados, 19 casos (73\%; 19/26) apresentavam deposição de $A \beta$ na parede dos vasos, sendo $100 \%$ (19/19) destes com marcação nos vasos da leptomeninge e $84 \%$ (16/19) apresentando marcação nos vasos do neurópilo. A parede dos vasos sanguíneos apresentou depósito de $A \beta$ na túnica média nos casos mais brandos, se estendendo para as demais camadas nos quadros mais severos. Nos vasos das leptomeninges, foi visualizada imunomarcação para $A \beta$ em parte da circunferência da túnica média, se estendendo para todo o vaso nos casos mais severos (Figura 9A). Os vasos do neurópilo imunomarcados incluíram artérias, de diferentes calibres, e capilares sanguíneos 
(Figura 9B). A CAA foi classificada de acordo com a severidade da deposição e camadas da parede do vaso acometidas, utilizando a classificação estabelecida por Vonsattel et al. (1991), variando de discreta a severa, podendo ainda apresentar extravasamento do $A \beta$ presente na parede dos vasos para o neurópilo adjacente, condição esta denominada alteração disórica (Figura 9C). Além disso, alguns vasos, principalmente aqueles do neurópilo, apresentaram separação das camadas da parede vascular, denominada "double barrelling" (Figura 9D). Dos 16 casos com CAA nos vasos do neurópilo, 87\% (14/16) apresentavam CAA severo com alterações disóricas em pelo menos uma das áreas analisadas do encéfalo. Em relação aos vasos da leptomeninge acometidos por CAA, 40\% apresentavam CAA discreto, $40 \%$ apresentavam CAA moderado, enquanto que em $20 \%$ dos casos a CAA era severa.

No que tange à idade dos cães, foi observada forte correlação entre a quantidade de deposição de $A \beta$ na parede dos vasos do neurópilo e a idade dos animais, sendo os animais mais velhos, os que possuíam maior área de deposição de $A \beta$ em vasos do neurópilo quando comparados aos mais jovens $(p<0,05$; $r^{2}=0,36$ ) (Figura 10). Quando avaliados somente os cães senis acima de oito anos de idade, em relação à área de deposição de $A \beta$ nos vasos do neurópilo, houve correlação positiva $\left(r^{2}=0,38\right)$.

$\mathrm{Na}$ avaliação da CAA nos vasos do neurópilo nos animais divididos em grupos relacionados a idade e porte, foi observado aumento mais expressivo da área de $A \beta$ nos vasos dos animais de pequeno porte, com média de $10.701 \mu \mathrm{m}^{2}$ nos animais de 8 a 12 anos e $81.811 \mu \mathrm{m}^{2}$ nos animais de 12 a 17 anos, seguido por aumento discreto nos animais de portes médio e grande, com o avançar da idade. Não foi observada diferença estatística na área de $A \beta$ depositada em vasos do neurópilo entre os córtices frontal, temporal e occipital ( $p>0,05)$ (Figura 10).

Foi observada associação entre a presença de micro-hemorragias perivasculares no encéfalo e a CAA no neurópilo $(p<0,05)$, onde $56 \%$ dos cães com CAA no neurópilo apresentavam áreas de micro-hemorragias perivasculares. Foi ainda demonstrado que os animais que apresentaram deposição de $A \beta$ na parede dos vasos do neurópilo tem nove vezes mais chance de apresentar microhemorragias perivasculares quando comparados aos animais sem CAA. 

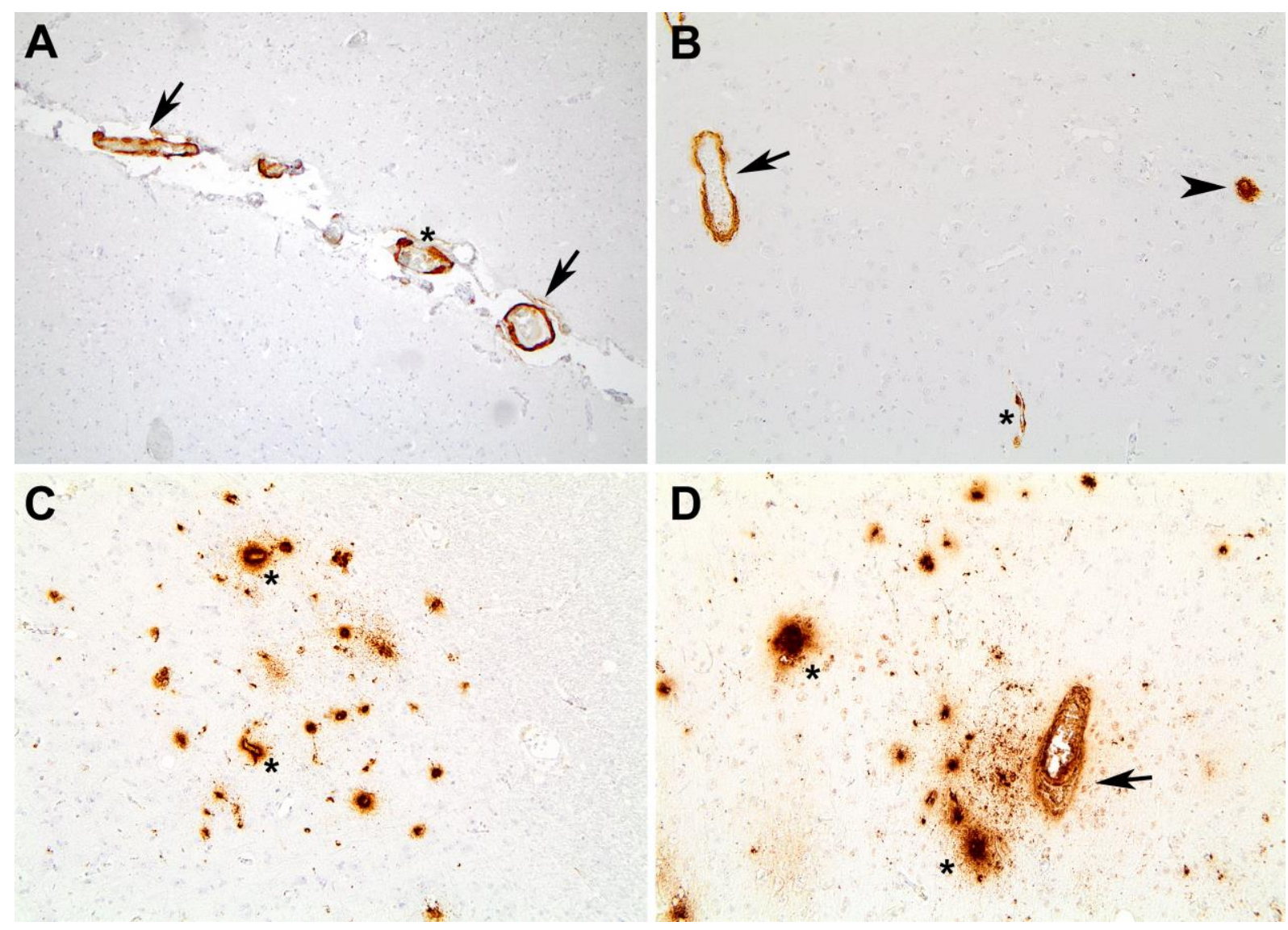

Figura 9 - Lesões no sistema nervoso central de cães senis detecção da deposição de $A \beta$ nos vasos do neurópilo e leptomeníngeos. (A) Deposição de $A \beta$ na túnica média dos vasos da leptomeninge do córtex occipital em um cão da raça Pitbull de 13 anos de idade (caso 24). É possível identificar um vaso com parte da circunferência de sua parede imunomarcada (asterisco), compatível com fase mais branda da CAA. (B) Deposição de A $\beta$ em arteríolas (seta) e capilares (asterisco e cabeça de seta) do neurópilo no córtex occipital de um cão sem raça definida de nove anos de idade (caso 11). (C) Deposição severa de $A \beta$ com alterações disóricas na parede de capilares do neurópilo do córtex occipital de um cão da raça Poodle de 14 anos de idade (caso 27). Na imagem é possível visualizar o lúmen dos capilares (asterisco). (D) Deposição severa de $A \beta$ com alterações disóricas na parede de capilares do neurópilo e arteríola do córtex occipital de um cão da raça Poodle de 17 anos (caso 32). Nota-se a separação das camadas da parede da arteríola, denominada "double barrelling" (seta). Pela severidade da deposição de $A \beta$ não é possível visualizar o lúmen dos capilares acometidos (asterisco). Objetiva: 20x. Fonte: (RODRIGUES, L.L, 2019).

No presente estudo, em $61 \%$ dos cães senis (16/26) havia deposição concomitante de $A \beta$ no neurópilo, sob a forma de placas, como nos vasos leptomeníngeos ou do neurópilo, os quais caracterizam a CAA. Somente em um cão (Caso no. 31) havia a deposição de $A \beta$ nos vasos do neurópilo e leptomeníngeos e ausência de deposição de $A \beta$ sob a forma de placas no neurópilo. Entretanto, não foi observada associação entre a presença da deposição de $A \beta$ no parênquima do SNC 
com a deposição na parede dos vasos $(p>0,05)$, nem entre a severidade na deposição de ambas ( $p>0,05)$. Dos 15 casos que apresentaram concomitantemente CAA e placas de $A \beta, 60 \%$ apresentavam os dois tipos de deposição em áreas coincidentes.

Frontal cortex

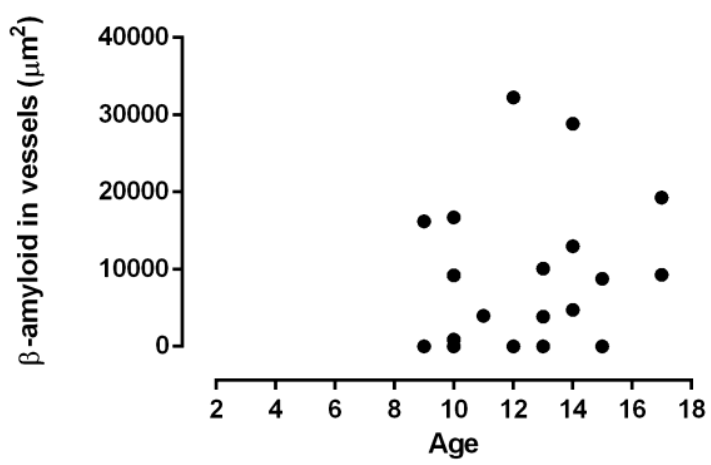

Occipital cortex

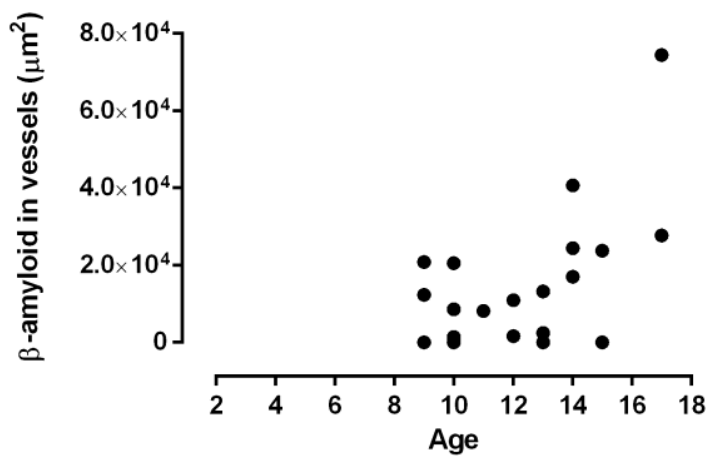

Temporal cortex

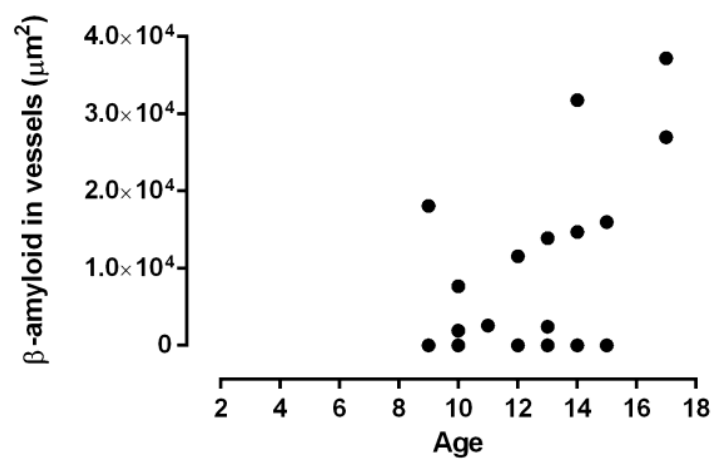

Total $\beta$-amyloid load in intracortical vessels

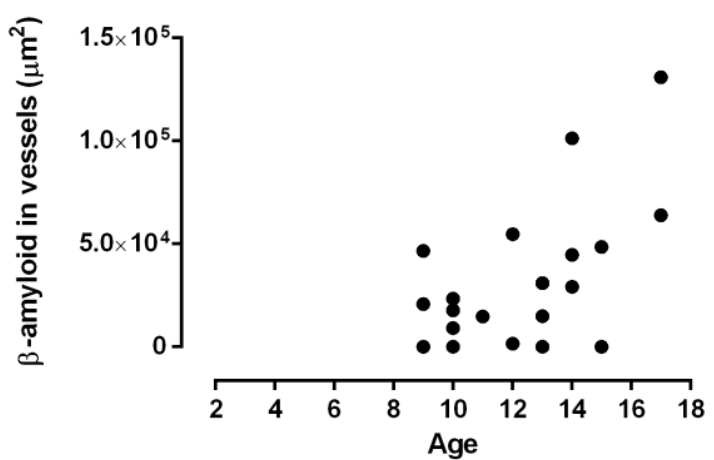

Figura 10 - Quantidade de deposição de $A \beta$ em vasos do neurópilo nas diferentes áreas do encéfalo de cães (córtices frontal, temporal, occipital e a totalidade de $A \beta$ nas três diferentes áreas). Foi observada forte correlação entre a quantidade de deposição de $A \beta$ na parede dos vasos do neurópilo e a idade dos animais, sendo os animais mais velhos, os que possuíam maior área de deposição de $A \beta$ em vasos do neurópilo quando comparados aos mais jovens $\left(p<0,05 ; r^{2}=0,36\right)$. Entretanto, não houve estatisticamente diferença na quantidade de $A \beta$ depositado nos vasos entre as diferentes regiões analisadas ( $p>0,05)$. Fonte: (RODRIGUES, L.L, 2019).

No que tange à reatividade de astrócitos, avaliado por meio da expressão da GFAP, foi identificada forte correlação positiva entre a astrocitose e a idade dos cães no presente estudo $\left(p<0,05 ; r^{2}=0,65\right)$, demonstrando que 0 grau de astrocitose aumentou com o avançar da idade. Foi também avaliada a relação entre a 
imunomarcação do encéfalo pela GFAP e Aß, não sendo observada correlação entre as marcações, mostrando desta forma que não há correlação entre a astrocitose e a área de deposição de $A \beta$, tanto no neurópilo, como na parede dos vasos $(p>0,05)$.

\subsection{DISCUSSÃO}

Os cães têm sido utilizados como modelo animal para estudos comparativos das doenças que são resultantes da deposição de $A \beta$ no encéfalo, tais como a doença de Alzheimer e CAA (OVERALL, 2000; BOSCH et al., 2012; HEAD et al., 2016). Entretanto, vários aspectos relacionados à deposição de $A \beta$ no encéfalo de cães, tais como áreas acometidas e relação entre CAA, placas senis, e idade, ainda não foram totalmente elucidados. No presente estudo, investigamos a deposição de $A \beta$ no encéfalo de cães idosos, de diferentes raças e idades, tanto sob a forma de placas senis como em vasos leptomeníngeos e do neurópilo.

No presente estudo, $A \beta$ foi detectado sob a forma de placas senis em cães a partir de nove anos de idade, em que houve uma correlação positiva entre 0 aumento de idade e área de deposição de $A \beta$ sob a forma de placas senis, considerando toda a população estudada. Semelhantemente, outros estudos apontam para um aumento da deposição de $A \beta$ em placas com o avançar da idade em cães (HEAD et al., 2000, 2016; SCHMIDT et al., 2015). Entretanto, quando se avaliou somente o grupo de cães acima de oito anos de idade e grupos normalizados pelo porte e raça, no presente estudo, não houve correlação entre o aumento da idade com a quantidade de $A \beta$ depositada sob a forma de placas senis. Isto provavelmente se deve a heterogeneidade da população de cães estudada, no que tange a raça e ao porte destes animais. A seleção de cães para o estudo da deposição de $A \beta$ pode ser um fator que contribui para a variabilidade individual resultando em uma falta de correlação entre idade e deposição de A (HEAD et al., 2000). Em cães, há uma correlação inversa entre expectativa de vida e tamanho do animal, sendo que os cães de grande porte são mais predispostos a doenças degenerativas e, portanto, possuem uma menor expectativa de vida (PATRONEK; WATERS; GLICKMAN, 1997).

Satou et al. (1997) demonstrou diferenças no padrão de deposição do $A \beta$ sob a forma de placas senis que evoluíam com a idade dos pacientes estudados, em uma população homogênea de cães, sendo a maioria da raça Beagle, em que havia 
um aumento na compactação das placas com o aumento da idade. Os tipos I e II foram mais frequentes nos cães até 15 anos e os tipos III e IV nos cães acima de 15 anos (SATOU et al., 1997). Outros autores, mesmo estudando populações heterogêneas de cães, também demonstraram a prevalência dos padrões III e IV em animais mais velhos (SCHMIDT et al., 2015; SCHÜTT et al., 2016). No presente estudo, não houve correlação entre a idade e o grau estabelecido por SATOU et al. (1997). O padrão IV, o qual está presente em cães mais velhos, foi detectado em cães abaixo de 15 anos neste estudo, sendo dois cães de porte médio, um SRD e um Buldogue Francês, de 10 e 13 anos respectivamente, e um cão de porte grande, da raça Golden Retriever, com nove anos de idade, refutando a afirmação de que os tipo IV, caracterizado pela deposição de placas compactas, acometem preferencialmente animais mais velhos. OZAWA et al. (2016) também não verificaram uma compactação das placas com o aumento da idade, uma vez que após os 14 anos foi observada uma mudança no padrão, com aumento de placas difusas (Satou I e II) no córtex cerebral dos cães acometidos. Em humanos, as placas inicialmente são detectadas do neocórtex e morfologicamente são classificadas como difusas, e nos estágios mais tardios da deposição, outros tipos de placas, tais como as placas neuríticas e dense-cored plaques, são detectadas (THAL et al., 2002). Entretanto, em cães não são observados depósitos de $A \beta$ sob a forma de dense-cored plaques, os quais estão associados às fases avançadas da $A D$ em humanos, sendo portanto, os cães modelos para a deposição inicial da $A \beta$ no encéfalo (SCHÜTT et al., 2016).

No presente estudo, não houve diferenças entre a quantidade de $A \beta$ depositado sob a forma de placas senis entre os córtices frontal, temporal e occipital, os quais pertencem ao neocórtex. Semelhantemente, em humanos, a fase inicial da deposição de $A \beta$, denominada fase 1 , as placas são exclusivamente encontradas no neocórtex (THAL et al., 2002). Numa fase mais avançada, a fase 2, além do envolvimento do neocórtex, há deposição de $A \beta$ no hipocampo (THAL et al., 2002). Porém, no presente estudo, $A \beta$ foi detectado no hipocampo de cães com os mais diversos graus de deposição de $A \beta$ no neocórtex, desde o grau Satou I até o grau $I V$, sendo que em um cão houve imunomarcação no hipocampo com ausência de $A \beta$ no neocórtex. Em cães da raça Beagle, verificou-se que a deposição de $A \beta$ ocorre inicialmente no córtex pré-frontal, e em estágios mais avançados, os córtices parietal e entorrinal também são acometidos, sendo o córtex occipital, o último a ser afetado 
pela deposição de $A \beta$ (HEAD et al., 2000). Diferentemente, ao utilizar uma população heterogênea de cães, os córtices frontal, temporal e occipital avaliados no presente estudo, foram igualmente afetados pela deposição de $A \beta$ sob a forma de placas senis, sem correlação da área afetada com a idade. Portanto, na avaliação de cães de diferentes raças e portes, não pôde ser estabelecido um padrão de deposição de $A \beta$ nas diferentes áreas do encéfalo, bem como sua relação com a idade dos cães.

A deposição de $A \beta$ na parede dos vasos sanguíneos do encéfalo (CAA), tanto do neurópilo como leptomeníngeos, têm sido amplamente discutida em humanos. Vasos de diferentes calibres podem ser acometidos, como artérias, arteríolas, capilares e raramente veias (VONSATTEL et al., 1991; JELLINGER, 2002; ATTEMS; JELLINGER; LINTNER, 2005). No presente estudo, a CAA foi detectada em 73\% dos cães idosos com idade acima de oito anos, destes $100 \%$ com deposição de $A \beta$ nos vasos das leptomeninges e $84 \%$ nos vasos do neurópilo. Da mesma forma, (SCHÜTT et al., 2016) observou em seu estudo que os vasos das leptomeninges eram mais frequentemente acometidos pela deposição de $A \beta$ do que os vasos do neurópilo. Foi observada correlação positiva entre o aumento de idade e a área de deposição de $A \beta$ nos vasos do neurópilo, tanto na avaliação de toda a população estudada como na avaliação dos animais acima de oito anos de idade. Diferentemente da deposição de $A \beta$ sob a forma de placas senis, quando os cães foram avaliados para CAA com normalização da idade pela raça e porte, foi observada correlação positiva entre área de deposição de $A \beta$ na parede dos vasos do neurópilo e a idade, com destaque para os cães de pequeno porte, onde o aumento da área foi mais expressivo com o avançar da idade do que os cães de portes médio e grande. Da mesma forma, outros estudos com cães com diversas raças demonstraram aumento na área e intensidade de deposição de $A \beta$ nos vasos do neurópilo com o avançar da idade (WEGIEL et al., 1995; PAPAIOANNOU et al., 2001; SCHMIDT et al., 2015; OZAWA et al., 2016; NEŠIĆ et al., 2017).

Além disso, igualmente à deposição de $A \beta$ no neurópilo sob a forma de placas, não houve diferença estatística entre o depósito de $A \beta$ nos vasos do neurópilo entre as diferentes áreas do córtex estudadas. Um estudo com 36 cães de diversas raças observou maior frequência de CAA no córtex frontal, porém não foram avaliados nesse estudo áreas relevantes ao acometimento por CAA, como córtex occipital e temporal (NEŠIĆ et al., 2017). Não há até o presente momento 
nenhum estudo que avalie amplamente as áreas do córtex quanto à distribuição da CAA que os autores do presente estudo tenham conhecimento. Em humanos, diversos autores observaram que a CAA é mais frequente no córtex occipital, seguido pelos córtices frontal, temporal e parietal (YAMADA et al., 1987; ATTEMS, 2005; VINTERS HV, 2013).

Neste estudo, foi observada associação entre a presença de CAA em vasos do neurópilo e micro-hemorragias perivasculares em cães, tendo os cães com CAA nove vezes mais chance de apresentarem micro-hemorragias perivasculares do que os cães sem deposição de $A \beta$ nos vasos do encéfalo. Estudos em humanos apontam que os vasos acometidos pela CAA podem apresentar diversas alterações morfológicas que comprometem sua função (CHARIDIMOU; GANG; WERRING, 2012). Nos casos de intensidade leve a moderada de deposição de $A \beta$ nos vasos, pode ser observado espessamento da parede do vaso com redução do lúmen dos vasos, levando a vasodilatação e vasoconstrição inadequadas. Já nos casos de deposição de $A \beta$ mais severos, há adelgaçamento da parede e dilatação do lúmen, com consequente fragilidade da parede vascular (WEGIEL et al., 1995; ZEKRY et al., 2003), levando a formação de micro-aneurismas e micro-hemorragias perivasculares (VONSATTEL et al., 1991). Um estudo com cães observou áreas de hemorragia próximas a vasos acometidos pela CAA (UCHIDA et al., 1990).

Apesar de $61 \%$ dos casos avaliados no presente estudo apresentarem concomitantemente deposição de $A \beta$ sob a forma de placas senis e em vasos, caracterizando a CAA, não foi identificada associação estatística significativa entre as duas formas de deposição de $A \beta$. Isso pode ser devido ao fato de haver apenas um animal que apresentou CAA sem deposição de $A \beta$ sob a forma de placas senis. Também não foi observada correlação entre a severidade na deposição de $A \beta$ sob as duas formas. Alguns estudos observaram correlação entre a deposição de $A \beta$ sob a forma de placas senis e em vasos (YOSHINO et al., 1993; SCHÜTT et al., 2016; OZAWA et al., 2016), ao passo que outro não observou relação entre os dois tipos de deposição (PAPAIOANNOU et al., 2001), sendo esta relação ainda pouco elucidada. Além disso, dos 15 casos avaliados no presente estudo que apresentaram concomitantemente CAA e placas de $A \beta, 60 \%$ apresentavam os dois tipos de deposição em áreas coincidentes, achado esse consistente com o que foi relatado por (SCHÜTT et al., 2016), mas conflitante com o estudo de (OZAWA et al., 2016), onde as deposições não apresentavam co-localização. 
Em humanos com $A D$, demonstrou-se que os astrócitos reativos podem estar intimamente relacionados à patogênese da formação de placas no neurópilo (NAGELE et al., 2003). No tocante a reação astrocitária, houve correlação positiva entre o aumento no número de astrócitos (astrocitose) com o avançar da idade. Entretanto, não houve correlação, no presente estudo, entre astrocitose e a deposição de Aß. Semelhantemente, PAPAIOANNOU et al. (2001) também observou, em cães, que houve correlação entre o aumento da marcação de GFAP e idade, que não estava associada à deposição de $A \beta$. Entretanto, não se pode excluir que os astrócitos, em cães, possam ter participação na patogênese das doenças associadas ao depósito de $A \beta$, mas que outras alterações encefálicas que ocorrem com o avançar da idade também podem ser associadas a esse aumento no número de astrócitos. Em cães, foi demonstrado que nas proximidades dos depósitos de $A \beta$, há uma resposta astrocitária importante (SCHMIDT et al., 2015). Ozawa et al. (2016) também verificou relação entre astrocitose e deposição de $A \beta$, além da correlação positiva entre astrocitose e idade.

No presente estudo, todos os cães acima de oito anos apresentavam pelo menos uma alteração microscópica no encéfalo relacionada ao envelhecimento, tais como degeneração e perda neuronal no hipocampo ou córtex, inclusão citoplasmática de lipofuscina, áreas de gliose difusa ou focais, espessamento e calcificação de meninges, vacuolização de substância branca e, espessamento da parede de vasos do neurópilo ou leptomeníngeos. Todos esses achados são comumente relatados em cães senis (BORRÀS et al., 1999; SCHMIDT et al., 2015; HEAD et al., 2016).

Em conclusão, o presente estudo demonstrou que a deposição de $A \beta$, sob a forma de placas senis ou CAA é extremamente heterogênea em cães de diferentes raças e portes. Além disso, o CAA em cães estava associado à presença de microhemorragias no encéfalo, demonstrado uma possível fragilidade vascular em decorrência da deposição de $A \beta$. Apesar de várias características da doença em cães serem semelhantes àquelas em observadas em humanos, a escolha da raça e porte para utilização como modelo animal pode interferir no padrão de deposição de $A \beta$ no encéfalo. 


\section{REFERÊNCIAS}

ATTEMS, J. Sporadic cerebral amyloid angiopathy: pathology, clinical implications, and possible pathomechanisms. Acta Neuropathologica, v. 110, n. 4, p. 345-359, 2005. Disponível em: <https://www.ncbi.nlm.nih.gov/pubmed/16170565>. Acesso em: 11/02/2019.

ATTEMS, J.; JELLINGER, K. A.; LINTNER, F. Alzheimer's disease pathology influences severity and topographical distribution of cerebral amyloid angiopathy. Acta Neuropathologica, v. 110, n. 3, p. 222-231, 2005. Disponível em :<https://www.ncbi.nlm.nih.gov/pubmed/16133541>. Acesso em: 11/02/2019.

CHARIDIMOU, A.; GANG, Q.; WERRING, D. J. Sporadic cerebral amyloid angiopathy revisited: recent insights into pathophysiology and clinical spectrum. Journal of Neurology, Neurosurgery and Psychiatry, v. 83, n. 2, p. 124-137, 2012. Disponível em: <https://www.ncbi.nlm.nih.gov/pubmed/22056963>. Acesso em: 11/02/2019.

BORRÀS, D.; FERRER, I; PUMAROLA, M. Age-related Changes in the Brain of the Dog. Veterinary Pathology, v. 36, n. 3, p. 202-211, 1999. Disponível em: $<$ https://journals.sagepub.com/doi/abs/10.1354/vp.36-3-202>. Acesso em: 15/02/2019.

HEAD, E.; McCLEARY, R.; HAHN, F. F.; MILGRAM, N. W.; COTMAN, C. W. Regionspecific age at onset of $\beta$-amyloid in dogs. Neurobiology of Aging, v. 21, n. 1, p. 89-96, 2000. Disponível em: <https://www.ncbi.nlm.nih.gov/pubmed/10794853>. Acesso em: 15/02/2019.

HEAD, E. et al. Pathology of the Aging Brain in Domestic and Laboratory Animals, and Animal Models of Human Neurodegenerative Diseases. Veterinary Pathology, v. $53, \quad$ n. 2 , p. 327-348, 2016. Disponível em: $<$ https://www.ncbi.nlm.nih.gov/pubmed/26869150>. Acesso em: 10/02/2019. 
SCHÜTT, T.; HELBOE, L.; PEDERSEN, L. O.; WALDEMAR, G.; BERENDT, M.; PEDERSEN, J. T. Dogs with Cognitive Dysfunction as a Spontaneous Model for Early Alzheimer's Disease: A Translational Study of Neuropathological and Inflammatory Markers. Journal of Alzheimer's Disease, v. 52, n. 2, p. 433-449, 2016. Disponível em: <https://www.ncbi.nlm.nih.gov/pubmed/27003213>. Acesso em: 11/02/2019.

JELLINGER, K. A. Alzheimer disease and cerebrovascular pathology: an update. Journal of Neural Transmission (Vienna), v. 109, n. 5-6, p. 813-836, 2002. Disponível em: <https://www.ncbi.nlm.nih.gov/pubmed/12111471>. Acesso em: 10/02/2019.

KUMAR, S.; FROST, J. L.; COTMAN, C. W.; HEAD, E.; PALMOUR, R.; LEMERE, C. A.; WALTER, J. Deposition of phosphorylated amyloid- $\beta$ in brains of aged nonhuman primates and canines. Brain Pathology, v. 28, n. 3, p. 427-430, 2018. Disponível em: <https://www.ncbi.nlm.nih.gov/pubmed/29740941>. Acesso em: 21/02/2019.

LANDSBERG G. M.; NICHOL, J.; ARAUJO, J. A. Cognitive dysfunction syndrome: a disease of canine and feline brain aging. Veterinary Clinics of North America: Small Animal Practice,v. 42, n. 4, p. 749-768. Disponível em: <https://www.ncbi.nlm.nih.gov/pubmed/22720812>. Acesso em: 27/02/2019.

NAGELE, R. G.; D'ANDREA, M. R.; LEE, H.; VENKATARAMAN, V.; WANG, H. Y. Astrocytes accumulate $A \beta 42$ and give rise to astrocytic amyloid plaques in Alzheimer disease brains. Brain Research, v. 971, n. 2, p. 197-209, 2003. Disponível em: <https://www.ncbi.nlm.nih.gov/pubmed/12706236>. Acesso em: 10/02/2019.

NEŠIĆ, S.; KUKOLJ, V.; MARINKOVIC,D.; VUCICEVIC, I; JOVANOVIC, M. Histological and immunohistochemical characteristics of cerebral amyloid angiopathy in elderly dogs. Veterinary Quaterly. v. 37, n. 1, p. 1-7, 2017 Disponível em: <https://www.ncbi.nlm.nih.gov/pubmed/27669976>. Acesso em: 10/02/2019. 
BOSCH, M. N.; PUGLIESE, M.; GIMENO-BAYÓN, J.; RODRIGUEZ, M. J.; MAHY, N. Dogs with cognitive dysfunction syndrome: a natural model of Alzheimer's disease. Current Alzheimer Research, v. 9, n. 3, p. 298-314, 2012. Disponível em: <https://www.ncbi.nlm.nih.gov/pubmed/21875411>. Acesso em: 12/02/2019.

OVERALL, K. L. Natural animal models of human psychiatric conditions: assessment of mechanism and validity. Progress in Neuro-Psychopharmacology \& Biologial Psychiatry. v. 24, n. 5, p. 727-776, 2000. Disponível em: <https://www.ncbi.nlm.nih.gov/pubmed/11191711>. Acesso em: 25/02/2019.

OZAWA, M.; CHAMBERS, J. K.; UCHIDA, L.; NAKAYAMA, H. The Relation between canine cognitive dysfunction and age-related brain lesions. Journal of Veterinary Medical Science, v. 78, n. 6, p. 997-1006, 2016. Disponível em: <https://www.ncbi.nlm.nih.gov/pmc/articles/PMC4937160/>. Acesso em: 10/02/2019.

PAPAIOANNOU, N.; TOOTEN, P. C.; VAN EDEREN, A. M.; BOHL, J. R.; ROFINA, J.; TSANGARIS, T.; GRUYS, E. Immunohistochemical investigation of the brain of aged dogs. I. Detection of neurofibrilary tangles ang of 4-hydroxynonenal protein, and oxidative damage product, in senile plaques. Amyloid, v. 8, n. 1, p. 11-21, 2001. Disponível em: <https://www.ncbi.nlm.nih.gov/pubmed/11293821>. Acesso em: 27/02/2019.

PATRONEK, G. J.; WATERS, D. J.; GLICKMAN, L. T. Comparative longevity of pet dogs and humans: implications for gerontology research. Journal of Gerontology Series A Biological Sciences and Medical Sciences, v. 52, n. 3, p. 171-178, 1997. Disponível em: <https://www.ncbi.nlm.nih.gov/pubmed/9158552>. Acesso em: 17/02/2019.

ROFINA, J. E.; SINGH, K.; SKOUMALOVA-VESELA, A.; VAN EDEREN, A. M.;VAN ASTEN, A. J.; WILHELM, J.; GRUYS, E. Histochemical accumulation of oxidative damage products is associated with Alzheimer-like pathology in the canine. Amyloid, v. 11, n. 2, p. 90-100, 2004. Disponível em: <https://www.tandfonline.com/doi/abs/10.1080/13506120412331285779>. Acesso em: 17/02/2019. 
SATOU, T.; CUMMINGS, B. J.; HEAD, E.; NIELSON, K. A.; HAHN, F. F.; MILGRAM, N. W.; VElASQUEZ, P.; CRIBBS, D. H.; TENNER, A. J.; COTMAN, C. W. The progression of $\beta$-amyloid deposition in the frontal cortex of the aged canine. Brain Research, v. 774 , n. 1-2, p. 35-43, 1997. Disponível em: <https://www.ncbi.nlm.nih.gov/pubmed/9452189>. Acesso em: 10/02/2019.

SCHMIDT, F.; BOLTZE, J; JAGER, C.; HOFMANN, S.; WILLEMS, N.; SEEGER, J.; HARTIG, W.; STOLZING, A. Detection and Quantification of $\beta$-Amyloid, Pyroglutamyl $A \beta$ and $T a u$ in Aged Canines. Journal of Neuropathology \& Experimental Neurology, v. 74, n. 9, p. 912-923, 2015. Disponível em: <https://www.ncbi.nlm.nih.gov/pubmed/26247394>. Acesso em: 10/02/2019.

SELKOE, D. J. Normal and abnormal biology of beta-amyloid precursor protein.. Annual review of biochemistry, v. 17, p. 489-517, 1994. Disponível em: <https://www.ncbi.nlm.nih.gov/pubmed/8210185>. Acesso em: 12/02/2019.

THAL, D. R.; RÜB, U.; ORANTES, M.; BRAAK, H. Phases of A beta-deposition in the human brain and its relevance for the development of AD. Neurology, v. 58, n.12, p. 1791-1800, 2002. Disponível em: <https://www.ncbi.nlm.nih.gov/pubmed/12084879>. Acesso em: 12/02/2019.

UCHIDA, K.; MIYAUCHI, Y.; NAKAYAMA, H.; GOTO, N. Amyloid angiopathy with cerebral hemorrhage and senile plaque in aged dogs. Nihon juigaku zasshi. The Japanese journal of veterinary science, v. 52, n. 3, p. 605-11, 1990. Disponível em: <http://europepmc.org/abstract/med/2385040>. Acesso em: 12/0/2019.

YOSHINO, T.; UCHIDA, K. TATEYAMA, S.; YAMAGUCHI, R.; NAKAYAMA. H,; GOTO, N. A retrospective study of canine senile plaques and cerebral amyloid angiopathy. Veterinary Pathology, v. 33, n. 2, p. 230-234, 1996. Disponível em: <https://www.ncbi.nlm.nih.gov/pubmed/8801718>. Acesso em: 10/02/2019. 
VINTERS H. V.; GILBERT, J. J. Cerebral amyloid angiopathy: incidence and complications in the aging brain: The distribution of amyloid vascular changes. Stroke, v. 14, n. 6, p. 924-928, 2013. Disponível em: $<$ https://www.ncbi.nlm.nih.gov/pubmed/6658996>. Acesso em: 12/02/2019.

VONSATTEL, J. P.; MYERS, R. H.; HEDLEY-WHYTE, E. T.; ROPPER, A. H.; BIRD, E. D.; RICHARDSON, E.P.Jr. Cerebral amyloid angiopathy without and with cerebral hemorrhages: A comparative histological study. Annals of Neurology, v. 30, n. 5, p. 637-649, 1991. Disponível em: <https://www.ncbi.nlm.nih.gov/pubmed/1763890>. Acesso em: 10/02/2019.

WEGIEL, J.; WISNIEWSKI, H. M.; OZIEWIATKOWSKI, J,; TARNASWSKI, M.; NOWAKOWSKI, J.; DZIEWIATKOWSKA, A.; SOLTYSIAK, Z. The origin of amyloid in cerebral vessels of aged dogs. Brain Research, v. 705, n. 1-2, p. 225-234, 1995. Disponível

em: $<$ https://www.sciencedirect.com/science/article/pii/0006899395011560>. Acesso em: 10/02/2019.

YAMADA, M. ; TSUKAGOSHI, H.; OTOMO, E.; HAYAKAWA, M.. Cerebral amyloid angiopathy in the aged. Journal of Neurology, v. 234, n. 6, p. 371-376, 1987. Disponível em: <https://www.ncbi.nlm.nih.gov/pubmed/3655840>. Acesso em: 12/02/2019.

ZEKRY, D.; DUYCKAERTS, C.; BELMIN, J.; GEOFFRE, C.; MOULIAS, R.; HAUW, J. J. Cerebral amyloid angiopathy in the elderly: vessel walls changes and relationship with dementia. Acta Neuropathologica, v. 106, n.4, p. 367-373, 2003. Disponível em: <https://www.ncbi.nlm.nih.gov/pubmed/12898153>. Acesso em: 12/02/2019. 
Apêndice 


\title{
Multiple infarcts and hemorrhages in the central nervous system of a dog with cerebral amyloid angiopathy: a case report
}

Laís Limeira Rodrigues*®i, Leonardo Pereira Mesquita, Rafael Carneiro Costa, Raquel Gonçalves Gomes,

Daniel Arrais Biihrer and Paulo César Maiorka

\begin{abstract}
Background: $\beta$-amyloid $(A \beta)$ can accumulate in the brain of aged dogs, and within vessels walls, the disease is called cerebral amyloid angiopathy (CAA). In humans, Alzheimer's disease and CAA are strongly correlated with cerebrovascular disease. However, in dogs, this association has not been extensively studied yet. The present report highlights the pathological and clinical features of a concomitant cerebrovascular disease and amyloid precursor protein (APP) accumulation in the brain of a dog.

Case presentation: A female, 16-year-old, Standard Poodle with a one-year history of cognitive deficits presented with an acute onset of right-sided postural reaction deficit and circling, left-sided head tilt, positional nystagmus, and ataxia. Due to poor prognosis the dog was euthanized, and pathological examination of the brain revealed an acute lacunar infarction within the thalamus extending to rostral colliculus. Additional findings included subacute and chronic areas of ischemia throughout the brain and areas of hemorrhage within the medulla. Immunolabeling revealed APP deposition within intraparenchymal vessels of frontal, temporal and occipital cortex, hippocampus, diencephalon, mesencephalon and myelencephalon, besides meningeal vessels walls. Glial fibrillary acidic protein (GFAP) immunolabeling showed marked astrocytosis around the acute area of infarction and within chronic areas of ischemia. Histological examination of the brain along with immunohistochemistry results showed a concomitant APP, which is an A $\beta$ precursor, accumulation within the neuroparenchyma and vessels (CAA) with histological evidences of a cerebrovascular disease in an aged dog.

Conclusions: This report shows that APP accumulation in the brain can occur concomitantly to a severe cerebrovascular disease in a dog. Further studies are necessary to elucidate if cerebrovascular disease is associated with $A \beta$ accumulation in the brain of dogs.
\end{abstract}

Keywords: Amyloid, CAA, Canine, Congophilic angiopathy, Ischemia, Stroke

\section{Background}

Cerebrovascular disease (CVD), defined as any abnormality of the central nervous system (CNS) resulted from pathologic processes that compromises the blood supply [1], is a well-recognized cause of disability in humans. Despite its relative rarity, CVD is now recognized as a cause of neurological disfunction in dogs and cats and can be either classified as ischemic or hemorrhagic [2, 3].

* Correspondence: lalimeira@gmail.com

Departament of Pathology, Faculdade de Medicina Veterinária e Zootecnia, Universidade de São Paulo, Av. Prof Dr. Orlando Marques de Paiva, 87, Săo Paulo 05508-270, Brazil
Vessel occlusion by thromboembolism resulting in ischemic stroke and vessel rupture causing hemorrhage are the main direct consequences of CVD in dogs and cats [3] Chronic hypertension, which results in atherosclerosis and lipohyalinosis in small penetrating arteries of the brain, is also suspected of being one of the main underlying conditions that may predispose dogs to CVD $[4,5]$. Other predisposing conditions may include neoplasia, sepsis, hypothyroidism, parasites, vascular malformation, and coagulopathy [4]

Cerebral amyloid angiopathy (CAA), which is characterized by the deposition of $\beta$-amyloid peptide $(A \beta)$ in 
parenchymal and leptomeningeal blood vessels, is a common disease in aged people, and associated with Alzheimer's disease (AD) [6]. In dogs, a condition like $\mathrm{AD}$, characterized by accumulation of senile plaques composed either by $A \beta$ or $A \beta$ precursor protein (APP), has been well described [7-12]. Importantly, the accumulation of $\mathrm{A} \beta$ within blood vessels (CAA), has also been reported in dogs $[7,10,11]$. In humans, CAA has been associated with vascular lesions, such as ischemic infarcts and intracerebral hemorrhages [6]. Intracerebral hemorrhages have also been reported in association with CAA in dogs [10]

Although infarcts, hemorrhages and white matter loss have been associated with CAA in humans [6], few studies have reported the occurrence of both brain infarcts and hemorrhages in dogs with CAA. The aim of the present study was to describe the clinical and pathological aspects of infarctions and hemorrhages within the CNS of a dog with APP deposition within vascular walls.

\section{Case presentation}

A female, 16-year-old, Standard Poodle was presented at a private veterinary clinic. The owner reported several changes in the mental status 1 year prior to clinical examination. These changes were recognized as confusion and reduced awareness, impaired recognition of human family members and loss of previously learned abilities. Two days prior to clinical examination, the animal presented with a generalized tonic-clonic seizure. Subsequently, the animal presented with a poor appetite and lethargy, with circling and ataxia.

The neurologic exam revealed acute right-sided abnormalities characterized by postural reaction deficit, circling, and head and neck turn in addition to left-sided head tilt, positional nystagmus, and ataxia. The owner declined to perform a magnetic resonance imaging exam.

The clinical signs evolved to lateral recumbency and the dog was unable to feed itself, characterizing a poor prognosis. Therefore, the dog was euthanized and submitted for necropsy at the Department of Pathology of the School of Veterinary Medicine and Animal Science (FMVZ), University of São Paulo (USP). The brain was entirely fixed in $10 \%$ buffered formalin and routinely processed for histology. Sections of the brain were stained with hematoxylin and eosin, and were also submitted for immunohistochemistry for detection of APP and glial fibrillary acidic protein (GFAP). Briefly, several sections of CNS were submitted to antigen retrieval with citrate buffer $\mathrm{pH}$ 6.0. Then, the slides were incubated with primary antibodies anti-APP (Millipore, Darmstadt, Germany) and anti-GFAP (Dako, Agilent, Santa Clara, California, USA) diluted at 1:200 and 1:14000, respectively. The antigen-antibody binding was visualized using EnVision FLEX System kit (Dako,
Agilent, Santa Clara, California, USA), according to manufacturer's instructions. As a positive control for APP staining, a brain of dog with traumatic brain injury with axonal degeneration was used. A brain of a young dog without significant histological lesions were used as negative control for APP labeling.

Grossly, the lateral ventricles were mildly distended, with flattened gyri and mild widening of sulci.

Histologically, intraparenchymal and leptomeningeal blood vessels from many areas of CNS, including the myelencephalon up to cerebral cortex were mildly to severely thickened by an acellular and hyaline material. On the right paramedian region, extending from the thalamus, at the level of diencephalon and mesencephalon junction to the oculomotor nucleus, at the level of rostral colliculus, there was a locally extensive, well demarcated, lacunar area with marked loss of neuroparenchyma tinctorial properties with coagulative necrosis surrounded by a rim of severe spongiosis (Fig. 1a). Within the area of necrosis, multifocally, neurons had a pyknotic nuclei and hypereosinophilic cytoplasm (neuronal necrosis). There was also necrosis and degeneration of glial and endothelial cells, characterized by pyknotic and karyorrhectic nuclei (Fig. 1b). The perivascular compartments of surrounding vessels were infiltrated by a low number of histiocytes (Fig. 1c). Within the area of spongiosis there was a large number of swollen axons forming axonal spheroids (axonal degeneration). GFAP immunolabeling showed an increase in the number complexity, and thickness of astrocytic process (astrogliosis) surrounding the necrotic lesion (Fig. 1d). Within the necrotic area, the astrocytic processes were not evident. GFAP was mildly detected within degenerated and necrotic astrocytes inside the necrotic area. These findings are compatible with an acute area of ischemia/ infarction with initial reactive gliosis with minimal inflammation.

Multifocally, lacunar areas of subacute infarction were visualized within the cerebellum, mainly involving the granular layer and adjacent white matter (Fig. 2a). The areas were characterized by a high number of granular cells with pyknotic and karyorrhectic nuclei, with liquefaction of neuropil, admixed with a moderate number of foam macrophages (Gitter cells) and axonal spheroids (Fig. 2b). These areas were surrounded by a moderate number of new-formed blood vessels with hypertrophied endothelial cells (neovascularization) with adjacent areas of hemorrhage and mild perivascular cuffing containing histiocytes. Prominent astrogliosis, demonstrated with GFAP immunolabeling, involving also the Bergman glia were visualized at the periphery of these necrotic areas (Fig. 2c).

Chronic lacunar areas of ischemia were also present within the telencephalon at the level of basal nuclei and 


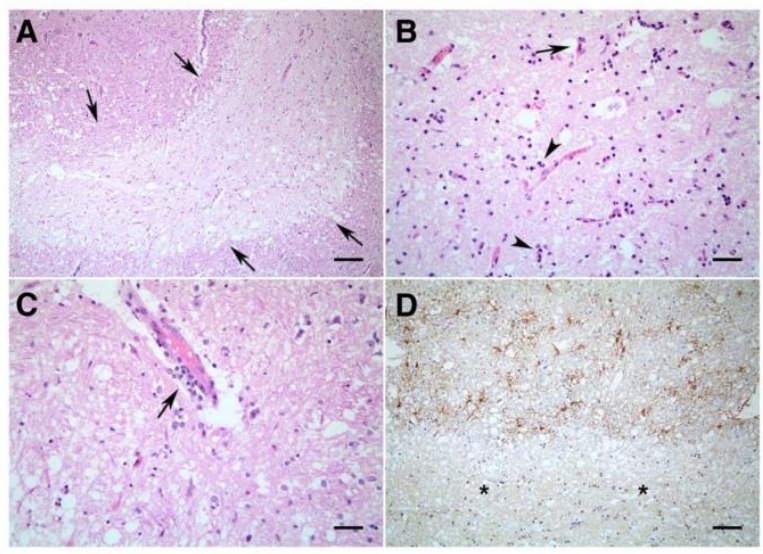

Fig. 1 Cerebral amyloid angiopathy in a dog: central nervous system lesions. A-C, hematoxylin and eosin staining. a. At the level of oculomotor nucleus, a well demarcated, lacunar area of acute ischemia with coagulative necrosis surrounded by a rim of severe spongiosis (arrows) was visualized. b. Within the infarcted area there was neuronal necrosis (arrow) and degeneration and necrosis of glial cells (arrowheads). c. Perivascular cuffing of a low number of histiocytes was detected in vessels around the infarcted area. $\mathbf{d}$. GFAP immunolabeling showed a severe astrogliosis (brown staining) surrounding the necrotic lesion (asterisks), in which astrocytic processes weren't evident. Scale bars, a - $200 \mu \mathrm{m}, \mathbf{b}-70 \mu \mathrm{m}, \mathbf{c}-50 \mu \mathrm{m}, \mathbf{d}-100 \mu \mathrm{m}$

hippocampus. These areas were pallor, well demarcated with neuron loss and with a marked proliferation of capillaries with hypertrophied endothelial cells. There was a mild to moderate spongiosis with an increase in the number of glial cells (gliosis), including a moderate number of cells with an abundant eosinophilic cytoplasm and an eccentric nuclei (gemistocytes). Rare perivascular cuffing of small number of histiocytes were visualized. Within these areas there was a marked increase in the number of astrocytes

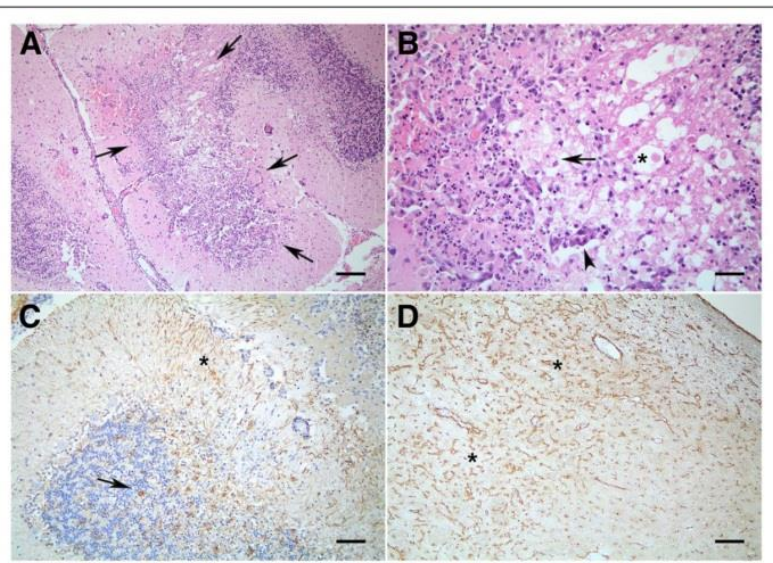

Fig. 2 Cerebral amyloid angiopathy in a dog: central nervous system lesions. A-B, hematoxylin and eosin staining. a. In the cerebellum, a lacuna area of subacute infarction was visualized involving the granular layer and adjacent white matter (arrows). $\mathbf{b}$. The subacute infarction was characterized by coagulative and liquefactive necrosis with Gitter cells (arrow), new-formed blood vessels (arrowhead) and axonal spheroids (asterisk). c. GFAP immunolabeling showed prominent astrogliosis (arrow), involving also the Bergman glia (asterisk). d In chronic areas of ischemia there was a marked increase in the number of astrocytes (astrocytosis) and astrogliosis as demonstrated by GFAP immunolabeling (asterisks). Scale bars, a, c, d - $200 \mu \mathrm{m}, \mathbf{b}-50 \mu \mathrm{m}$ 
(astrocytosis) and astrogliosis as demonstrated by GFAP immunolabeling (Fig. 2d).

In additional to the areas of ischemia/infarcts, within the medulla at the level of obex, there were multifocal areas of hemorrhage within the reticular formation and several nuclei (Fig. 3). The white matter of many areas, including telencephalon to the myelencephalon, were variably degenerated.

APP immunolabeling were visualized more frequently within the wall of intraparenchymal blood vessels (Fig. 4a), and occasionally affecting leptomeningeal vessels. Intensity of APP immunolabeling varied from mild to severe, according to Attems [6]. APP affected vessels from many areas of the CNS, but had a patchy distribution, characterized by APP-positive areas with adjacent APP-negative areas. Frontal lobes and temporal lobes were more affected when compared to occipital lobes. Other affected areas included the hippocampus, diencephalon, mesencephalon and myelencephalon. The cerebellum was less affected. Rarely, vessels with dyschoric change were observed, which consists in additional spreading of APP from vessels to adjacent neuropil (Fig. 4b). Importantly, a large number of hyalinized vessels weren't immunolabeled for APP, especially those with a higher wall thickness. Within the periphery of the acute infarction, swollen and degenerating axons were immunolabeled for APP (Fig. 4c).

At the level of rostral commissure (basal nuclei) and thalamus there are locally extensive areas where a multifocal staining for APP was visualized within the neuroparenchyma. Within these areas, two types of APP staining were seen. Small, up to $25 \mu \mathrm{m}$ in diameter, areas of staining containing a round, dense and darkly stained central region (Fig. 4d) were visualized in addition to other labeled areas, in which a central darkly stained core was not present (Fig. 4e) [13].

The brain of a young dog used as negative control didn't exhibit APP immunostaining within CNS vessels or within the neuroparenchyma (Fig. 4f).

\section{Discussion and conclusions}

The diagnosis of CAA was based on histological changes observed in blood vessels, and by demonstration of APP by immunohistochemistry within the wall of these vessels. In dogs, similarly as in humans, $A \beta$ is derived from APP [14]. Therefore, in the present study, the detection of APP highly suggests an ongoing cerebrovascular disease associated with $\mathrm{A} \beta$ deposition. Besides vascular walls, APP immunolabeling was also visualized within the neuroparenchyma in some areas of the CNS in the dog from the present study. Importantly, this dog had histological lesions related to vascular injury, such as areas of ischemia/infarctions and hemorrhages.

Several neurological changes, like those observed in humans have been described in the CNS of old dogs (reviewed by Vite and Head [15]). These pathologica changes, among others, includes $\mathrm{A} \beta$ deposits, CAA vascular disease, and infarcts [15]. The post-mortem examination of 16-year-old dog from the present study that presented with acute neurological signs prior to death, revealed that this dog had a severe CAA, in addition to intraparenchymal $\mathrm{A} \beta$ deposits, which are found in AD. In humans, these disorders are correlated with each other, and the prevalence of CAA in $\mathrm{AD}$ is over $70 \%$ [6]. The severity of CAA has been correlated with progressing $\mathrm{AD}$ pathology [16]. In dogs, a condition

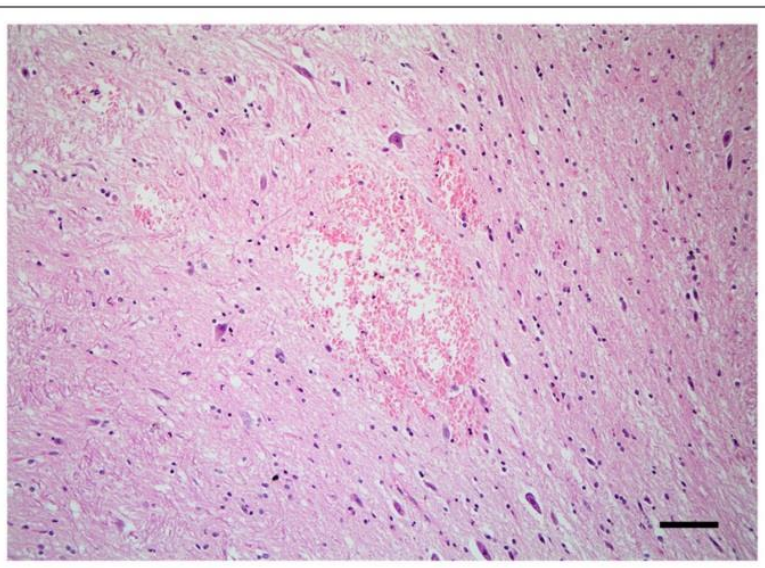

Fig. 3 Cerebral amyloid angiopathy in a dog: central nervous system lesions. Hematoxylin and eosin staining. Multifocal hemorrhages within the medulla at the level of the obex. Scale bar, $100 \mu \mathrm{m}$ 


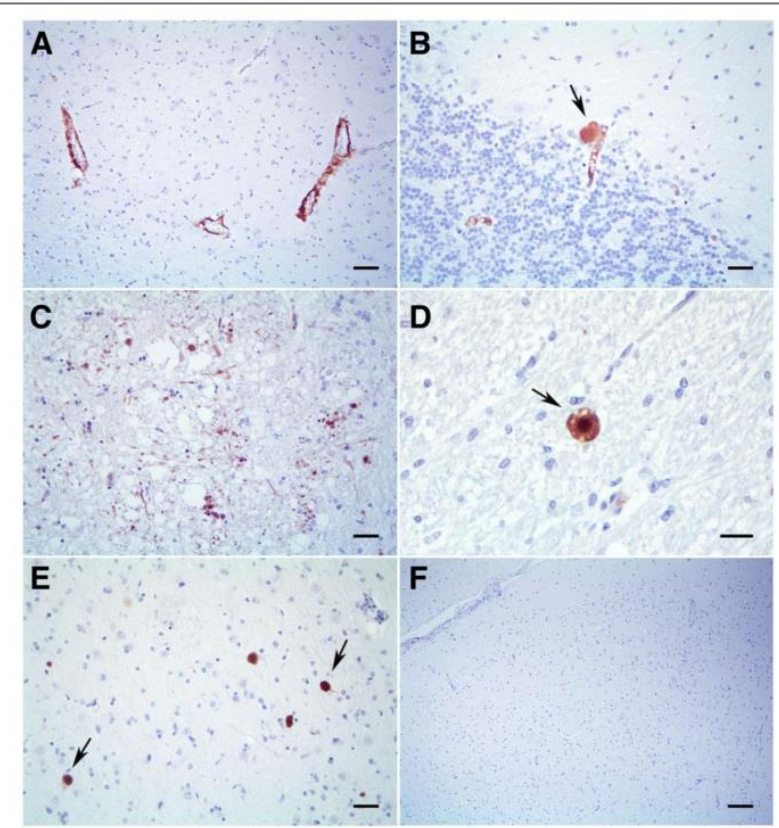

Fig. 4 Cerebral amyloid angiopathy in a dog: detection of amyloid precursor protein (APP). a. The wall of intraparenchymal blood vessels was strongly immunolabeled for APP (brown staining). b. Additional spreading of APP from vessels to adjacent neuropil (arrow) of cerebellum was visualized. c. Swollen and degenerating axons were immunolabeled for APP within the periphery of the acute infarction. $\mathbf{d}$. Small, up to $25 \mu \mathrm{m}$ in diameter, areas of immunolabeling for APP containing a round, dense and darkly stained central region was detected. e. Other round areas of APP immunolabeling within the neuroparenchyma without a darkly stained central region was also detected. $\mathbf{f}$. The brain of a control dog didn't exhibit immunolabeling for APP. Scale bars, a $-70 \mu \mathrm{m}, \mathbf{b}, \mathbf{c}, \mathbf{e}-50 \mu \mathrm{m}, \mathbf{d}-50 \mu \mathrm{m}, \mathbf{f}-200 \mu \mathrm{m}$

like $\mathrm{AD}$ in humans, with deposition of $\mathrm{A} \beta$ plaques has been described [7-12]. Similarly, A $\beta$ deposition within the wall of intraparenchymal and meningeal vessels, resulting in CAA was reported in dogs $[7,10,11]$.

In addition to $C A A$ and $A \beta$ deposits in the brain, the dog from the present report had several areas of ischemia/infarction and hemorrhages in the brain. In humans, CAA has been associated with these vascular disorders [6]. In CAA, elastic elements and smooth muscle are replaced by $A \beta$ deposition, which could induce aneurysms and consequently intracerebral hemorrhages [6]. In dogs, intracerebral hemorrhage has been associated with CAA [10].

In the present study, the cerebral ischemic infarcts had a lacunar distribution, demonstrating that intraparenchymal, small and penetrating arteries were the most likely affected vessels. In a previous study, the cause of lacunar infarcts in dogs couldn't be determined [17]. Ischemic cerebral infarcts have been observed in patients with CAA, which could be a risk factor for cerebral infarcts in aged people [18]. Although the exactly pathogenic mechanism of occurrence of ischemic infarcts associated with CAA is not known [6], A $\beta$ could induce loss of vascular reactivity resulting in a more severe ischemia, with reduction of collateral circulation in ischemic tissues at risk for infarction [19]. In the present case, thickened and hyalinized, intraparenchymal and meningeal vessels that were not immunolabeled for APP were visualized in the dog from the present report. Histologically, these vessels resemble those found in aged people with vascular dementia [20]. Although CAA could contribute for development of ischemic injury in the present case, we cannot rule out other vascular pathological processes. There is an increase evidence of overlapping of $\mathrm{AD}$ and cerebrovascular lesions [21]. Vascular changes in the aged brains can be found in a significant proportion of $\mathrm{AD}$ patients [20]. Cerebrovascular lesions and $\mathrm{AD}$ may coexist in earlier stages of cognitive impairment and may influence its severity and progression, thus making its diagnosis challenging even for neuropathologists [21].

The dog from the present report had cognitive deficits for 1 year such as impaired recognition of human family 
members and loss of previously learned abilities. Multiple subacute and chronic areas of ischemia in the brain of this dog, as evidenced by astrocytic reactivity within these areas, demonstrates that this dog was suffering from an ongoing cerebrovascular disease. The cognitive deficits presented by this dog are most likely due to $A \beta$ deposition in the brain and neuronal loss due to the multiple old areas of ischemia [15]. However, the dog presented acute neurological signs, and at neurological exam had an ipsilateral postural reaction deficit, ipsilateral circling, and head and neck turn with contralateral head tilt, positional nystagmus, and ataxia. These signs are probably due to the acute ischemic infarct histologically visualized extending from the thalamus to the diencephalon and mesencephalon junction. Similar clinical signs were observed in dogs with midbrain/thalamic infarcts [17]

In conclusion, this report shows a concomitant neurodegenerative disease characterized by APP deposition, which is an $A \beta$ precursor, within the neuroparenchyma and vessels with a severe cerebrovascular disease in an aged dog. Further studies are necessary to elucidate the relationship between vascular disease and $A \beta$ accumulation in the brain of dogs.

\section{Abbreviations}

AD: Alzheimer's disease; APP: amyloid precursor protein; AB: $\beta$-amyloid; CAA: cerebral amyloid angiopathy; CNS: central nervous system; CVD: cerebrovascular disease; FMVZ: Department of Pathology of the School of Veterinary Medicine and Animal Science; GFAP: glial fibrillary acidic protein; USP: University of São Paulo

\section{Acknowledgements}

Not applicable.

\section{Funding}

\section{Not applicable.}

Availability of data and materials

All data generated from this study are included in the published article, including patient date.

\section{Authors' contributions}

LLR wrote the clinical report and drafted the manuscript. LPM, RCC, RGC an DAB performed the pathological and immunohistochemical examination PCM conducted and critically revised the manuscript. All authors read and approved the final manuscript

Ethics approval and consent to participate

The patient owner's provided written, informed consent for the clinical assessment, euthanasia and necropsy of their dog.

Consent for publication

Not applicable.

Competing interests

The authors declare that they have no competing interests.

Publisher's Note

Springer Nature remains neutral with regard to jurisdictional claims in published maps and institutional affiliations.
Received: 24 January 2018 Accepted: 19 November 2018

Published online: 27 November 2018

References

1. Kalimo H, Kaste M, Haltia M. Vascular diseases. In: Graham DI, Lantos PL, editors Greenfield's neuropathology. 7th ed. London: Arnold; 2002. p. 233-80.

2. Garosi LS. Cerebrovascular disease in dogs and cats. Vet Clin North Am Small Anim Pract. 2010;40(1):65-79.

3. Boudreau CE. An update on cerebrovascular disease in dogs and cats. Vet Clin North Am Small Anim Pract. 2018;48(1):45-62.

4. Wessmann A, Chandler K, Garosi L. Ischaemic and haemorrhagic stroke in the dog. Vet J. 2009;180(3):290-303.

5. Garosi L, McConnell JE, Platt SR, Barone G, Baron JC, de Lahunta A, et al. Results of diagnostic investigations and long-term outcome of 33 dogs with brain infarction (2000-2004). J Vet Intern Med. 2005:19(5):725-31.

6. Attems J. Sporadic cerebral amyloid angiopathy: pathology, clinica implications, and possible pathomechanisms. Acta Neuropathol. 2005; 110(4):345-59.

7. Yoshino T, Uchida K, Tateyama S, Yamaguchi R, Nakayama H, Goto N. A retrospective study of canine senile plaques and cerebral amyloid angiopathy. Vet Pathol. 1996;33(2):230-4.

8. Cummings BJ, Head E, Ruehl W, Milgram NW, Cotman CW. The canine as an animal model of human aging and dementia. Neurobiol Aging. 1996;17(2):259-68.

9. Okuda R, Uchida K, Tateyama S, Yamaguchi R, Nakayama H, Goto N. The distribution of amyloid beta precursor protein in canine brain. Acta Neuropathol. 1994:87(2):161-7.

10. Uchida K, Miyauchi Y, Nakayama H, Goto N. Amyloid angiopathy with cerebral hemorrhage and senile plaque in aged dogs. Nihon Juigaku Zassh

11. Uchida K, Tani Y, Uetsuka K, Nakayama H, Goto N. Immunohistochemica studies on canine cerebral amyloid angiopathy and senile plaques. J Vet Med Sci. 1992;54(4):659-67.

12. Yu CH, Song GS, Yhee JY, Kim JH, Im KS, Nho WG, et al. Histopathological and immunohistochemical comparison of the brain of human patients with Alzheimer's disease and the brain of aged dogs with cognitive dysfunction. J Comp Pathol. 2011;145(1):45-58

13. Garcia-Marin V, Blazquez-Llorca L, Rodriguez JR, Boluda S, Muntane G, Ferre I, et al. Diminished perisomatic GABAergic terminals on cortical neurons adjacent to amyloid plaques. Front Neuroanat. 2009:3:28.

14. Cummings BJ, Su JH, Cotman CW, White R, Russell MJ, Beta-amyloid accumulation in aged canine brain: a model of early plaque formation in Alzheimer's disease. Neurobiol Aging. 1993;14(6):547-60.

15. Vite $\mathrm{CH}$, Head E. Aging in the canine and feline brain. Vet Clin North Am Small Anim Pract. 2014:44(6):1113-29.

16. Attems J, Jellinger KA, Lintner $F$. Alzheimer's disease pathology influences severity and topographical distribution of cerebral amyloid angiopathy. Act Neuropathol. 2005:110(3):222-31.

17. Garosi L, MCConnell JF, Platt SR, Barone G, Baron JC, de Lahunta A, et al. Clinical and topographic magnetic resonance characteristics of suspected brain infarction in 40 dogs. J Vet Intern Med. 2006;20(2):311-21.

18. Cadavid D, Mena H, Koeller $K$, Frommelt RA. Cerebral beta amyloid angiopathy is a risk factor for cerebral ischemic infarction. A case control study in human brain biopsies. J Neuropathol Exp Neurol. 2000:59(9):768-73.

19. Zhang F, Eckman C, Younkin S, Hsiao KK, ladecola C. Increased susceptibility to ischemic brain damage in transgenic mice overexpressing the amyloid precursor protein. J Neurosci. 1997;17(20):7655-61.

20. Roman G, Kalaria R. Vascular determinants of cholinergic deficits in Alzheimer disease and vascular dementia. Neurobiol Aging, 2006;27(12):1769-85.

21. Attems J, Jellinger KA. The overlap between vascular disease and Alzheimer's disease-lessons from pathology. BMC Med. 2014;12:206. 